REVIEW

\title{
A Historical Overview of the Classification, Evolution, and Dispersion of Leishmania Parasites and Sandflies
}

\author{
Mohammad Akhoundi ${ }^{1}$, Katrin Kuhls ${ }^{2}$, Arnaud Cannet ${ }^{3}$, Jan Votýpka ${ }^{4,5}$, Pierre Marty ${ }^{1,3}$, \\ Pascal Delaunay ${ }^{1,3}$, Denis Sereno ${ }^{6,7}$
}

1 Service de Parasitologie-Mycologie, Hôpital de l'Archet, Centre Hospitalier Universitaire de Nice, Nice, France, 2 Division of Molecular Biotechnology and Functional Genetics, Technical University of Applied Sciences Wildau, Wildau, Germany, 3 Inserm U1065, Centre Méditerranéen de Médecine Moléculaire, Université de Nice-Sophia Antipolis, Nice, France, 4 Biology Centre, Institute of Parasitology, Czech Academy of Sciences, Prague, Czech Republic, 5 Department of Parasitology, Faculty of Science, Charles University in Prague, Prague, Czech Republic, 6 MIVEGEC, UMR CNRS-IRD-Université de Montpellier Centre IRD, Montpellier, France, 7 UMR177, Centre IRD de Montpellier, Montpellier, France

*m.akhoundi@yahoo.com

\section{Abstract}

\section{Background}

The aim of this study is to describe the major evolutionary historical events among Leishmania, sandflies, and the associated animal reservoirs in detail, in accordance with the geographical evolution of the Earth, which has not been previously discussed on a large scale.

\section{G Open access}

Citation: Akhoundi M, Kuhls K, Cannet A, Votýpka J, Marty P, Delaunay P, et al. (2016) A Historical Overview of the Classification, Evolution, and Dispersion of Leishmania Parasites and Sandflies. PLoS Negl Trop Dis 10(3): e0004349. doi:10.1371/ journal.pntd.0004349

Editor: Anne-Laure Bañuls, Institut de Recherche pour le Développement, FRANCE

Published: March 3, 2016

Copyright: @ 2016 Akhoundi et al. This is an open access article distributed under the terms of the Creative Commons Attribution License, which permits unrestricted use, distribution, and reproduction in any medium, provided the original author and source are credited.

Funding: The author(s) received no specific funding for this work.

Competing Interests: The authors have declared that no competing interests exist.

\section{Methodology and Principal Findings}

Leishmania and sandfly classification has always been a controversial matter, and the increasing number of species currently described further complicates this issue. Despite several hypotheses on the origin, evolution, and distribution of Leishmania and sandflies in the Old and New World, no consistent agreement exists regarding dissemination of the actors that play roles in leishmaniasis. For this purpose, we present here three centuries of research on sandflies and Leishmania descriptions, as well as a complete description of Leishmania and sandfly fossils and the emergence date of each Leishmania and sandfly group during different geographical periods, from 550 million years ago until now. We discuss critically the different approaches that were used for Leishmana and sandfly classification and their synonymies, proposing an updated classification for each species of Leishmania and sandfly. We update information on the current distribution and dispersion of different species of Leishmania (53), sandflies (more than 800 at genus or subgenus level), and animal reservoirs in each of the following geographical ecozones: Palearctic, Nearctic, Neotropic, Afrotropical, Oriental, Malagasy, and Australian. We propose an updated list of the potential and proven sandfly vectors for each Leishmania species in the Old and New World. Finally, we address a classical question about digenetic Leishmania evolution: which was the first host, a vertebrate or an invertebrate? 


\section{Conclusions and Significance}

We propose an updated view of events that have played important roles in the geographical dispersion of sandflies, in relation to both the Leishmania species they transmit and the animal reservoirs of the parasites.

\section{Introduction}

Leishmaniases are vector-borne diseases caused by obligate protozoan parasites from the genus Leishmania (Trypanosomatida: Trypanosomatidae). Leishmaniases are endemic in large areas of the tropics, subtropics, and the Mediterranean basin, including more than 98 countries, where there are a total of 350 million people at risk and 12 million cases of infection. Canine leishmaniasis is a serious problem, and it is estimated that 2.5 million dogs are infected in the Mediterranean basin only [1]. Among the endemic regions on five continents, there is an estimated incidence of 0.7-1.2 million cases of cutaneous leishmaniasis (CL) and 0.2-0.4 million cases of visceral leishmaniasis (VL) in these countries [2]. The disease is absent in New Zealand and the southern Pacific. Leishmaniasis is transmitted by the bite of infected female sandflies, whose hosts are animals such as canids, rodents, marsupials, hyraxes, or human beings. Approximately 53 Leishmania species have been described (without considering the synonyms and including all five subgenera and complexes: Leishmania, Viannia, Sauroleishmania, $L$. enriettii complex, and Paraleishmania); of these, 31 species are known to be parasites of mammals and 20 species are pathogenic for human beings. Leishmania parasites cause four main clinical forms of the disease-according to the location of the parasite in mammalian tissuesreferred to as visceral, cutaneous, diffuse cutaneous, and mucocutaneous leishmaniasis. The most common form is cutaneous disease, and the ten countries of Afghanistan, Algeria, Colombia, Brazil, Iran, Syria, Ethiopia, North Sudan, Costa Rica, and Peru together account for $70 \%$ to $75 \%$ of the global estimated CL incidence [2]. Regarding visceral leishmaniasis, more than $90 \%$ of all cases occur in just the six countries of India, Bangladesh, Sudan, South Sudan, Brazil, and Ethiopia [2]. Leishmaniasis currently constitutes a major global public health problem, showing an increasing burden over the last decade [2].

Leishmaniasis has a long history, dating to 2,500 B.C., with several primitive descriptions of the disease having been found in ancient writings and recent molecular findings from ancient archeological material. A detailed history of Leishmania descriptions is gven in Table 1.

Comprehension of the evolutionary relationships between sandflies and Leishmania is crucial for the future prediction of Leishmania transmission patterns, leishmaniasis epidemiology, and for developing intervention and control strategies. To achieve such an understanding, better information on the worldwide distribution of Leishmania parasites in relation to their sandfly vectors and intermediate hosts will be required. It is therefore necessary to obtain information on the origin of Leishmania and phlebotomine sandflies and their chronological history of coevolution. In this paper, we present a detailed review of the relevant literature on the Phlebotominae and Leishmania and update and discuss theories on their classification, origin, evolution, and dispersion.

\section{Sandflies}

Among more than 800 recognized sandfly species, approximately 464 species are found in the New World and 375 in the Old World [3,4]. The classification of both Old and New World sandflies has historically been based mainly on a phenetic approach to identifying overall similarity relationships between genera and subgenera, rather than on ancestor-descendant relationships. This approach has led to a proliferation of taxa, particularly at the subgeneric level, 
Table 1. History of Leishmania descriptions.

\begin{tabular}{|c|c|}
\hline Century & Author (Year): Description \\
\hline B.C. & $\begin{array}{l}\text { (2,500 to 1,500 B.C.): First description of conspicuous lesions similar to current cutaneous leishmanisis (CL) lesions. (2,000 B.C.): Leishmania } \\
\text { donovani infection in ancient Egyptian and Christian Nubian mummies. (1,500 B.C.): Report of Leishmania DNA in northern Sudan. (800 B.C.): } \\
\text { Leishmania infection in a 6-year-old girl mummy in Peru. (700 B.C.): Similar descriptions of CL discovered on tablets from King Ashurbanipal. } \\
\text { (650 B.C.): Records of what seems to be CL in the Tigris-Euphrates basin. }\end{array}$ \\
\hline A.D. & $\begin{array}{l}\text { (First century A.D.): Evidence for the presence of the cutaneous form of the disease in Ecuador and Peru, South America. Avicenna (10th century A. } \\
\text { D.): Description of cutaneous lesions called Balakh sore and probability of mosquito intervention. (15th and 16th centuries A.D.: Inca period): } \\
\text { Notification of "valley sickness," "Andean sickness," or "white leprosy," which are likely to be South American CL. }\end{array}$ \\
\hline
\end{tabular}

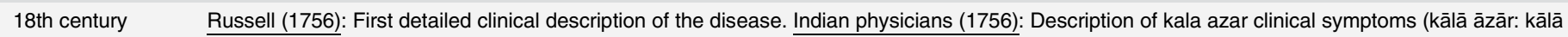
meaning black and āzār meaning fever or disease). Cosme Bueno (1764): First suspicions reporting the probable role of phlebotomine sandflies in disease transmission in the New World.

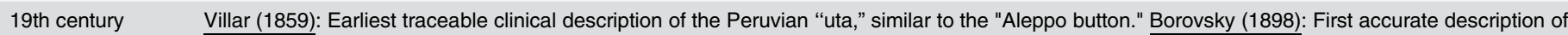
the causative agent of the oriental sore, reference to Protozoa.

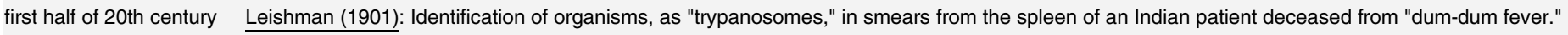
Donovan (1901): Confirms the presence of what became known as Leishman-Donovan bodies in the smears from Indian patients. First description of the link between Leishman-Donovan bodies and kala azar. Ross (1903): Proposed the name of Leishmania donovani for the Leishman-Donovan bodies. Wright (1903): Description of Helcosoma tropica (L. tropica). Leishman and Rogers (1904): Demonstrated oval intracellular amastigotes can differentiate into flagellated promastigotes. Rogers (1904): First successful in vitro cultivation of the flagellated forms. Laveran and Chatoin (1904): First case of kala azar in the Mediterranean region. Sergent and colleagues (1905): First report of CL transmited by sandflies of the Phlebotomus genus. Patton (1907): Evidence of the presence of Leishman-Donovan bodies in peripheral blood lymphocytes and its flagellated forms in the sandfly's gut. Nicolle (1908): Isolation of Leishmania parasites from a child or "infant," leading to name Leishmania infantum. Differentiation between the Mediterranean visceral leishmaniasis caused by $L$. infantum and the Indian kala azar due to L. donovani. Nicolle and Comple (1908): Isolation of Leishmania parasites from infected dogs. Lindenberg, Carini, and Paranhos (1909): Confirm the presence of autochthonous cutaneous leishmaniasis, "Baurú ulcer," in the Americas. Wenyon (1911): Incrimination of Phlebotomus as the probable vector of diseases caused by Leishmania in the Old World. Splendore (1911): Leishmania as the causative agent of mucocutaneous lesions "Espundia." Vianna (1911): Description of L. braziliensis. Migone (1913): First report of visceral leishmaniasis in the Americas. Yakimoff and Schokhor (1914): Proposition of the names L. tropica minor and L. tropica major to separate parasites causing "dry urban" and "wet rural" cutaneous leishmaniasis. Casteliani and Chalmers (1919): L. donovani archibaldi as the ethiological agent of a lethal form of visceral leishmaniasis. Aragão (1922): Reproduced in a dog the clinical signs of leishmaniasis by injecting squashed infected sandflies. Montenegro (1923): Experimental inoculation of L. braziliensis, introduction of the intradermal test (Montenegro skin test), still in use for the diagnosis of leishmaniasis. Penna (1934): First record of the Amazonian visceral leishmanaisis. Chagas (1936): Description of visceral leishmaniasis in Brazil. Cunha and Chagas (1937): Isolation of L. chagasi from Brazilian VL. Swaminath and colleagues (1942): Demontrated the process of Leishmania transmition to humans by sandflies using a group of volunteers. Hoare (1948): Demonstrated the Leishmania circulation in sandflies, indicating the flagellates being set free and multiplying in the sandfly intestine; the infection later is caused through the posterior station (like Trypanosoma cruzi). Kirk (1949): Classification of Leishmania according to their morphology, culture characteristics, clinical and epidemiological aspects of infections in human and other natural hosts, cross-immunity, serological tests, and xenodifferentiation. Propose a complete nomenclature of the Leishmania genus and their synonyms.

second half of 20th century
Biagi (1953): Discription of various Leishmania species. Pessôa (1961): Present the first list of known Leishmania species in the Americas. Use of the trinomial system for Leishmania. Adler (1962): Reports transient cryptic infections in mice by L. adleri, which usually infects lizards, that lead to the proposal of the evolution of Leishmania species infecting mammals from reptilian parasites. Adler (1963 and 1964): Differentiates $L$. tropica, L. mexicana, and L. braziliensis with serological techniques. Proposed a taxonomy for Leishmania infecting hummans and lizards. Shaw (1964): Demostrates the transmission of Endotrypanum schaudinni by Phlebotomus species. Hoare and Wallace (1966): Introduced new terms for the description of the Leishmania developmental stages. Lainson and Shaw (1970): Subdivide Leishmania species into two groups: "fastgrowing (L. mexicana)" and "slow-growing (L. braziliensis)." Lainson and Shaw (1972): First proposal of complexes of species for Neotropical Leishmania causing CL: the mexicana complex and the braziliensis complex. Schnur and colleagues (1972): serotype Leishmania with promastigotes excreted factors. Ranquein (1973): First proposal of a separate genus for Sauroleishmania. Bray (1973): Use the systematic concept for description of Leishmania species. Vickerman (1976): Proposed Leishmania that do not infect mammals as "not strictly being" Leishmania species, giving the status "Incertae sedis" to Leishmania isolated from reptiles. Gardener (1977): Proposed a taxonomy of the Leishmania genus that includes nomenclature, classification, and synonomies for the principal species and a list of species that do not normally infect humans. Hommel (1978), Wilson and Southgate (1979): Consider the identification and nomenclature under two titles of "traditional" and "modern" taxonomic criteria. Consider parasites that do not infect mammals as "not strictly being" Leishmania species. Lainson and Shaw (1979): Proposed a revised classification for American Leishmania species, based on their developmental patterns in Lutzomyia longipalpis. Subdivision into three groups: (i) Hypopylaria (L. agamae and and L. ceramodactyli), (ii) Peripylaria (L. braziliensis complex), (iii) Suprapylaria ( $L$. donovani, $L$. mexicana, L. hertigi, and L. tropica complexes). Tait (1980): Suggests sexual recombination in trypanosomatids. Saf'janova (1982): Created a subgenus of Leishmania and proposed the term of Sauroleishmania Ranque, 1973 for parasites infecting lizards. Le Blancq and Peters (1986): Consider isoenzyme electrophoresis as a discriminatory system for Leishmania identification. Lainson and Shaw (1987): Division of Leishmania genus into two subgenera, based on the developmental pattern of Leishmania in the sand fly's gut: Leishmania (Suprapylorian) and Viannia (Peripylorian). Rioux and colleagues (1990): New classification of the Leishmania genus based on the use of intrinsic and extrinsic characters with Linnean and Adansonian methods. WHO (1990): Categorised the Leishmania species into three subgenera: Leishmania, Sauroleishmania, and Viannia. Momen (1993): Proposes the synonimy of L. chagasi (responsible for VL in the New World) and $L$. infantum. Shaw (1994): Proposes that the genus Leishmania encompass 30 species infecting mammals and 21 species infecting human. Cupolillo and colleagues (1994): Describe the monophyly of the subgenus Viannia. Dedet and colleagues (1999): Categorize the history of Leishmania classification into four periods of Linnean classifications, Adansonian classifications, phenetic classifications, and phylogenetic classifications.

(Continued) 
Table 1. (Continued)

\begin{tabular}{|c|c|}
\hline Century & Author (Year): Description \\
\hline 2000 until now & $\begin{array}{l}\text { Cupolillo and colleagues (2000), Schoenian and colleagues (2010): Leishmania genus composed of two groups: (i) Euleishmania } \\
\text { (Leishmania and Viannia subgenera) and (ii) Paraleishmania (L. hertigi, L. deanei, L. colombiensis, L. equatorensis, L. herreri, } \\
\text { and Endotrypanum species). Moreira and colleagues (2004): Present an updated classification of kinetoplastid protists. Fraga } \\
\text { and colleagues (2010): New concepts, based on molecular data, concerning the reduction of the number of species, } \\
\text { suppression of some species, and downgrading some to subspecies level. Kuhls and colleagues (2011), Leblois and } \\
\text { colleagues (2011): Import of L. infantum (ca. } 500 \text { years ago) from the Old World (namely Portugal) to the New World as a result } \\
\text { of finding a suitable vector there. Lukeš and colleagues (2014): Trypanosomatidae family consists of } 13 \text { genera: Trypanosoma, } \\
\text { Phytomonas, Leishmania, Leptomonas, Crithidia, Blastocrithidia, Herpetomonas, Sergeia, Wallacemonas, Blechomonas, } \\
\text { Angomonas, Strigomonas, and Kentomonas. }\end{array}$ \\
\hline
\end{tabular}

doi:10.1371/journal.pntd.0004349.t001

and to the simplification and incorporation of higher taxonomic categories into species. Sandflies belong to the order Diptera, suborder Nematocera, family Psychodidae, and subfamily Phlebotominae. Initially, studies on phlebotomine sandfly taxonomy were exclusively based on morphological aspects of dead specimens. Because of the introduction of several new methods, such as chromosome analysis, multivariate morphometrics, laboratory rearing and colonization, isoenzyme, molecular and phylogenetic analysis and, more recently, mass spectrometry, our knowledge of phlebotomine sandfly systematics has increased. These advances have led to better identification and classification of sandfly specimens, which together with an appreciation of sandfly flight range (approximately $1.5 \mathrm{~km}$ per day), have helped to clarify the intraspecific and interspecific variations within sandfly subgenera and populations. A large portion of the literature regarding phlebotomine sandfly systematics addresses their general classification and relationships with other groups [3,5-8] as well as the phylogenetics of the Psychodidae, based on insect fossils [9], phlebotomine sandfly evolution [5], phenetic and phylogenetic analyses of phlebotomine sandflies [10], and the molecular systematics and phylogenetic relationships of phlebotomines using DNA analysis [11]. Many classification systems for phlebotomine sandflies have been proposed since that of Newstead 1911, including those of Abonnenc, Davidson, Fairchild, Leng, Lewis, Quate, and Theodor. However, despite this extensive literature, there is no universal agreement regarding the ranking of taxa above the species level.

The history of sandfly taxonomy can be roughly divided into two distinct periods (Table 2). During the first period, taxa were distinguished according to the analysis of certain external structures (e.g., the structure of the male genitalia, wing venation indices and other external measurements, known as phlebotometry). In the second period, descriptions of internal structures such as the spermathecae, cibarium, and the pharynx were employed [12]. Based on the classification performed by Theodor [6,13], Lewis et al. [14] have proposed subdivision of the phlebotomine sandflies into two genera for Old World species, Phlebotomus (Rondani) and Sergentomyia (França), and three genera for New World species, Lutzomyia (França), Brumptomyia (França and Parrot), and Warileya (Hertig). The genus Chinius (Leng, 1987) belongs to a distinct taxon that is used for some Chinese sandfly species with primitive characters [15]. Rispail and Léger [10] proposed a new genus and subgenus classification for Old World sandflies, based on a morphological study suggesting their division into seven genera, including Phlebotomus, Australophlebotomus, Idiophlebotomus, Spelaeophlebotomus, Sergentomyia, Spelaeomyia, and Chinius (Table 2). In addition to the mentioned classification, some subgenera from the genus Phlebotomus, such as Abonnencius and Legeromyia, have been recently described and could be retained until a complete classification is proposed for the entire genus Phlebotomus. 
Table 2. History of sandfly descriptions.

\begin{tabular}{|c|c|}
\hline Century & Author (Year): Description \\
\hline 17th century & Bonanni (1691): First recognizable description of a sandfly as a species of Culex, or mosquito. \\
\hline 18th century & $\begin{array}{l}\text { Linnaeus (1735): Description of Angioptera in the insect order that includes the Tipulary flies. Scopoli (1786): Description of } \\
\text { Phlebotomus papatasi (Bibio papataci) as first species of described "Psychodidae," with no mention of a particular } \\
\text { classification level. Latreille (1796): Description of the "Pschoda" genus that diverges from Bibio and Tipula. }\end{array}$ \\
\hline $\begin{array}{l}\text { first half of 19th } \\
\text { century }\end{array}$ & $\begin{array}{l}\text { Meigen (1818): Description of the Muchen (Tipularia) family that encompasses: Eulermuchen, Gallmucken (Gallicolae). Latreille } \\
\text { (1825): Changed Tipulariae into Nemocera (Nematocera) family that included the tribe of Tipulariae and the group of } \\
\text { Gallicolae (Psychode). Newman (1834): Gathered Psychoda genus in the order of Psychodite (Currently known as } \\
\text { Psychodidae). Rondani (1840): Named sandflies as "Flebotomus" and put them into the tribe of Flebotomidae, family of } \\
\text { Flebotominae. Renamed later as "Phlebotomus" by Lewis (1845). Rondani (1843): Includes sandflies in the tribe of Tipulidae, } \\
\text { family of Hebotomina. Loew (1844): Description of Haemasson minutus (Sergentomyia minuta) that belongs to the family of } \\
\text { "Tipularia gallicola," Psychodina. Walker (1848): Gathered Psychoda and Sycorax in the family of Tipularia, Noctuaeforme. } \\
\text { Zetterstedt (1850): Includes Psychoda genus into the Psychodidae family. }\end{array}$ \\
\hline $\begin{array}{l}\text { second half of 19th } \\
\text { century }\end{array}$ & $\begin{array}{l}\text { Walker (1851): Considered the Phlebotomidae as a family belonging to Diptera. Bigot (1854), Rondani (1864), Schiner (1864): } \\
\text { Gathered Phloebotomus, Psychoda, and some other genera in the Psychodidae family. Rondani (1856): Separation of the } \\
\text { Phloebotomidae into Phloebotomina and Psychodina. Walker (1856): Gathered Sycorax and Psychoda and some other genera } \\
\text { in the Phlebotomidae family. Loew (1862): Subdivided the Psychodidae family into Psychodina and Phlebotomina. Philippi } \\
\text { (1865): Included the Psychoda genus into the "Tipularia gallicola" family. Hennig (1872): Proposed to use the name } \\
\text { "Psychodites" as the generic name of fossil sandflies. Rondani (1873): Classification of sandflies into the Tipulidae tribe, family } \\
\text { of Hebotomina (probably a syntax error). Eaton (1895), Kertesz (1902): Subdivided the Psychodidae into the Psychodinae and } \\
\text { Phlebotominae subfamilies. }\end{array}$ \\
\hline $\begin{array}{l}\text { first half of 20th } \\
\text { century }\end{array}$ & 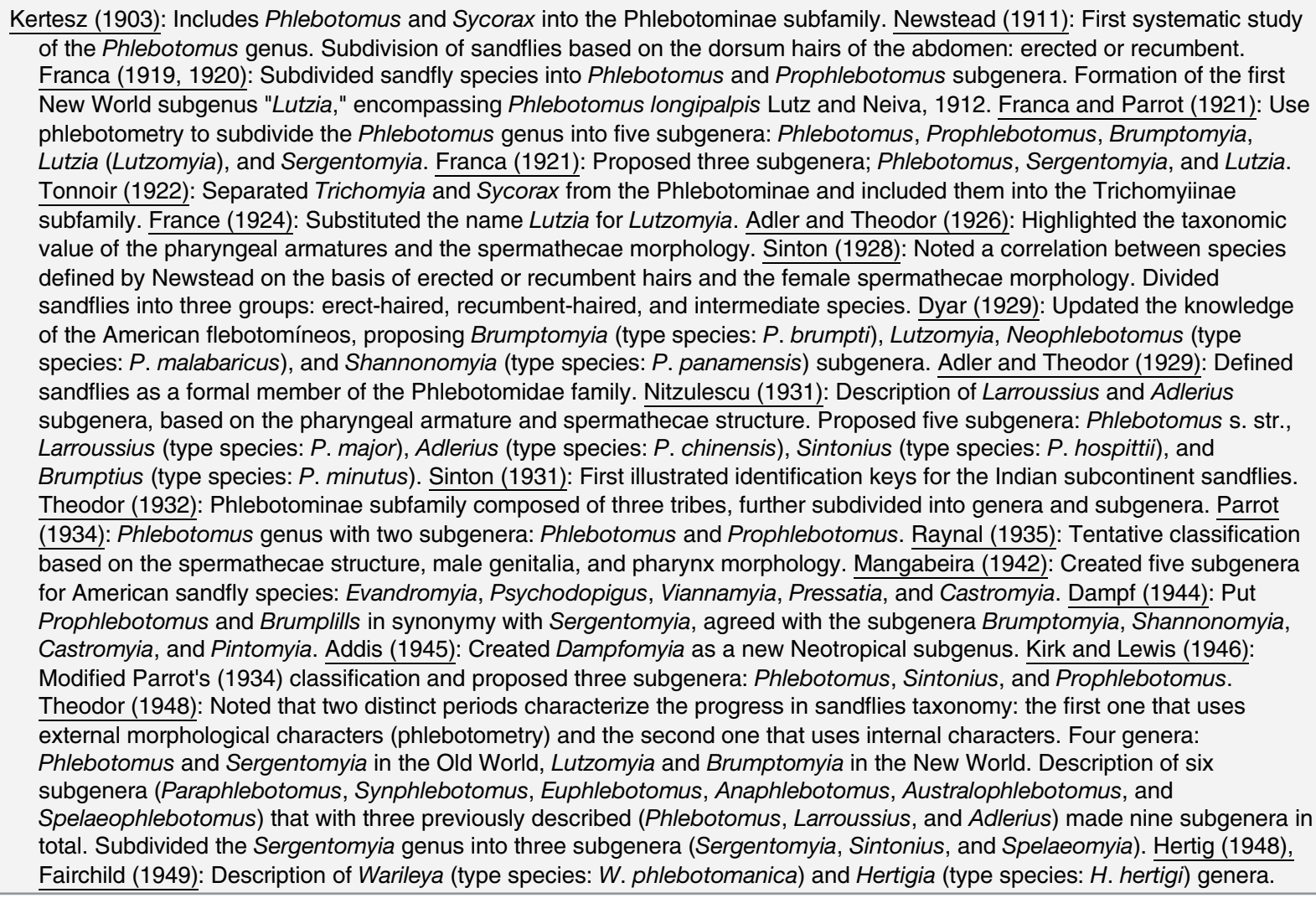 \\
\hline
\end{tabular}


Table 2. (Continued)

\begin{tabular}{|c|c|}
\hline Century & Author (Year): Description \\
\hline $\begin{array}{l}\text { second half of 20th } \\
\text { century }\end{array}$ & 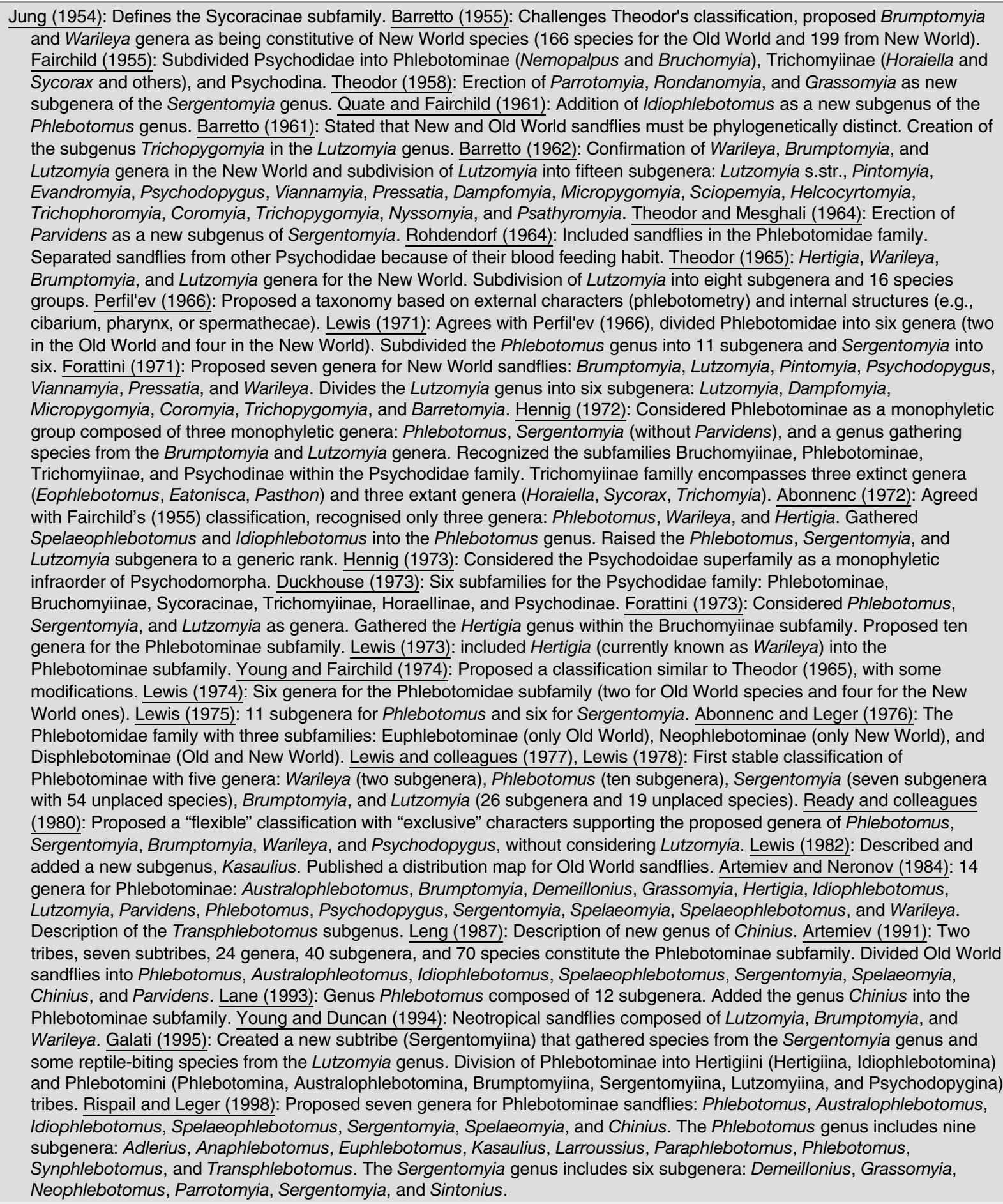 \\
\hline 2000 until now & $\begin{array}{l}\text { Galati (2003): Proposed to subdivide the Phlebotominae familly into two tribes: Hertigiini (subtribes of Hertigiina and } \\
\text { Idiophlebotomina) and Phlebotomini (subtribes of Phlebotomina, Australophlebotomina, Brumptomyiina, Sergentomyiina, } \\
\text { Lutzomyiina, and Psychodopygina). Galati (2009): Upgraded many of the Lutzomyia subgenera, cited in Young and Duncan, } \\
\text { 1994, to a generic status. Galati (2014): Revised the classification proposed by Galati, 2003, leading to an increase in genera } \\
\text { numbers. }\end{array}$ \\
\hline
\end{tabular}

doi:10.1371/journal.pntd.0004349.t002 
A classification first proposed by Lewis et al. [14] and later reviewed by Young and Duncan [8] subdivides the Neotropical sandflies into Lutzomyia, Brumptomyia, and Warileya. This classification is still accepted by a majority of sandfly taxonomists. A new system of classification has been proposed by Galati [3], who revised the existing proposals for New World sandflies. The system recognized 464 species of Neotropical phlebotomine sandflies, grouped into 23 genera, 20 subgenera, three species groups, and 28 series. This classification includes a complete review and reorganization of the subfamily Phlebotominae, which is further classified into two tribes, Hertigiini (Hertigiina and Idiophlebotomina subtribes) and Phlebotomini (Phlebotomina, Australophlebotomina, Brumptomyiina, Sergentomyiina, Lutzomyiina, and Psychodopygina subtribes).

In 2014, Galati revised her previous publication and proposed a new version of classification for Phlebotominae sandflies [3,16]. Based on her classification, the Phlebotomini tribe includes 931 extant species (916 valid species and 15 with uncertain taxonomic status) classified in six subtribes:

- Phlebotomina (Phlebotomus genus, 110 spp.)

- Australophlebotomina (Australophlebotomus genus, ten spp.)

- Brumptomyiina (Brumptomyia [26 spp.] and Oligodontomyia [three spp.] genera)

- Sergentomyiina (Sergentomyia [310 spp.], Deanemyia [five spp.], and Micropygomyia [55 spp.] genera)

- Lutzomyiina (Sciopemyia [eight spp.], Lutzomyia [74 spp.], Migonemyia [seven spp.], Pintomyia $[57$ spp.], Dampfomyia [20 spp.], Expapillata [two spp.], Pressatia [eight spp.], Trichopygomyia [16 spp.], and Evandromyia [42 spp.] genera)

- Psychodopygina (Psathyromyia [43 spp.], Viannamyia [four spp.], Martinsmyia [11 spp.], Bichromomyia [six spp.], Psychodopygus [40 spp.], Nyssomyia [20 spp.], and Trichophoromyia [39 spp.] genera).

The genus Edentomyia, including one species (Edentomyia piauiensis), was described by Galati [3] without indicating the taxonomic position in the Phlebotomini tribe.

The Hertigiini tribe contained two subtribes of Hertigiina (Warileya and Hertigia genera) and Idiophlebotomina (Spelaeophlebotomus, Idiophlebotomus, and Chinius genera), with five genera and 28 extant species.

Currently, a conservative approach based on practical criteria has led to subdivision of the Phlebotominae into six genera: three genera from the Old World (Phlebotomus [13 subgenera], Sergentomyia [ten subgenera], and Chinius [four species]) and three from the New World (Lutzomyia [26 subgenera and groups], Brumptomyia [24 species], and Warileya [six species]) (Fig 1) $[8,17]$. This classification is currently widely used.

\section{Old World Sandflies}

The Old World sandflies include three genera: Phlebotomus, Sergentomyia, and Chinius, which are found in the Palaearctic, Afrotropical, Malagasy, Oriental, and Australian regions.

Genus Phlebotomus (Rondani and Berté, 1840) includes 13 subgenera: Adlerius, Anaphlebotomus, Australophlebotomus, Euphlebotomus, Idiophlebotomus, Kasauliuls, Larroussius, Madaphlebotomus, Paraphlebotomus, Phlebotomus, Spelaeophlebotomus, Synphlebotomus, and Transphlebotomus (Fig 1). They are present only in the Old World and are particularly prevalent in the Palaearctic region, which is the main temperate area of the Old World. Most Phlebotomus species are inhabitants of semiarid and savannah areas rather than forests. Therefore, 


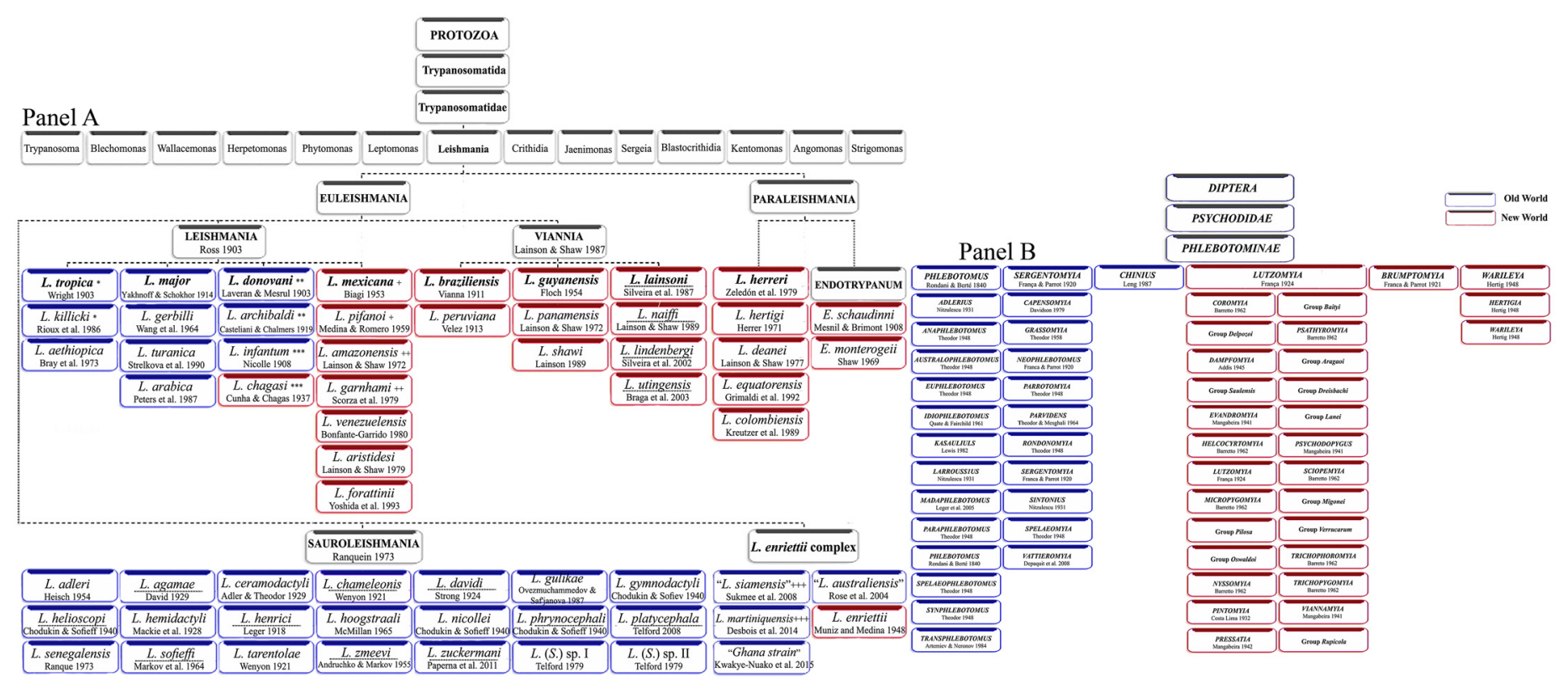

Fig 1. Updated classification of Leishmania and sandfly. Panel A. Classification of Leishmania species. Panel B. Phlebotominae sandfly classification, according to Theodor [6,13], Quate and Fairchild [163], Theodor and Mesghali [22], Lewis [5], Leng [15], and Young and Duncan [8].

doi:10.1371/journal.pntd.0004349.g001 
1. The Palaearctic region: species belonging to the Phlebotomus genus are dominant in the Palaearctic region, as it is the main temperate area of the Old World. Nearly 200 sandfly species belong to various Phlebotomus subgenera; Adlerius, Anaphlebotomus, Euphlebotomus, Idiophlebotomus, Larroussius, Paraphlebotomus, Phlebotomus, Synphlebotomus, and Transphlebotomus, as well as the Chinius and Sergentomyia genera, are found in the Palaearctic region. (Iran [6,21,22], Pakistan [23], the former U.S.S.R. [12], France [24], Turkey [25], Morocco [26], Yemen [27], Spain [28], Tunisia [29], Afghanistan [30], Saudi Arabia [31], Iraq [32], Algeria [33], Egypt [34], Greece [35], China [15,40], Jordan [4,10,36-39].)

2. The Afrotropical region: subgenera of Anaphlebotomus, Larroussius, Paraphlebotomus, Phlebotomus, Spelaeophlebotomus, and Synphlebotomus from the genus Phlebotomus, together with the genus Sergentomyia, are distributed in this region. Surprisingly, however, some Phlebotomus species that are known to be inhabitants of this region are absent from western Afrotropical regions. (Gabon [41], Sudan [17], Central African Republic [4,10,39,42], Ethiopia [43], Southern Africa [44].)

3. The Malagasy region (Madagascar and nearby Indian Ocean islands): Species belonging to the genera of Phlebotomus (Anaphlebotomus and Madaphlebotomus subgenera) and Sergentomyia are present in this region. Despite their presence, no sandfly species has been reported as a disease vector in this region [45].

4. The Oriental region: Approximately 122 sandfly species belonging to the Phlebotomus, Chinius, and Sergentomyia genera are present in this region. In the mainly dry western area, the sandfly fauna is essentially Eremian (The Eremian zone has an arid climate, and its vegetation ranges from barely vegetated desert and hills to a variety of semiarid shrub savannas, semiarid tussock grasslands, and hummock grasslands). In eastern India, Phlebotomus argentipes is an important vector of kala azar. In the far eastern area, including Vietnam, sandflies known to bite humans are rare or absent, and there appear to be rather few phlebotomine species in this area, with the exception of the Philippines [46,47,48].

5. The Australian region: the Australasian phlebotomine fauna is bipolar in origin, with the genus Phlebotomus (Australophlebotomus: eight spp.) originating from the south and the subgenus Idiophlebotomus (one sp.) and Sergentomyia (24 spp.) from the north [49]. The co-occurrence of some sandfly species (e.g., S. hoogstraali, S. vanella) in both Australia and New Guinea supports the hypothesis proposed by Schodde and Calaby [50] regarding the simultaneous development of the New Guinea sandfly fauna along with the eastern Australia sandflies. Sandflies are generally abundant in both regions where there is rainfall of less than $635 \mathrm{~mm}$, as well as in the wetter northern zone, where the dry season is long. These areas, unlike the Eremian zone of the northern hemisphere, support only a few Phlebotomus species, and humans and livestock are rarely attacked (New Guinea [49,51-53]).

\section{New World Sandflies}

The New World sandflies include three genera: Lutzomyia, Warileya, and Brumptomyia, which are found in the Nearctic and Neotropical regions:

Genus Lutzomyia Franca, 1924. This is a large genus, with nearly 434 species and several subgenera, including the Coromyia (Delpozoi group), Dampfomyia (Saulensis group), Evandromyia, Helcocyrtomyia, Lutzomyia, Micropygomyia (Pilosa and Oswaldoi groups), Nyssomyia, Pintomyia, Pressatia (Baityi group), Psathyromyia (Aragaoi, Dreisbachi, and Lanei groups), Psychodopygus, Sciopemyia (Migonei and Verrucarum groups), Trichophoromyia, Trichopygomyia, and 
Viannamyia (Rupicola group), as well as some ungrouped species (Fig 1). The Lutzomyia genus is more diverse than its Old World counterparts. Nevertheless, vector species are found only in some subgenera (Nyssomyia, Psychodopygus, and Lutzomyia s.str.). Sandflies are of little importance in temperate North America but are abundant in tropical America. Lutzomyia is the most important genus in terms of species diversity and medical importance and exhibits a wide dispersion area. Species of this genus are found only in the New World, with a distribution ranging from the southern areas of the Nearctic region throughout the Neotropical ecozone. Sandflies are found mainly in forest areas in Central and South America. Wide morphological variations have been described for Lutzomyia species, which are greater than those of the Old World species. Therefore, the classification of Lutzomyia species remains largely unresolved and relies on divisions based on morphological taxonomic characters that are still controversial.

Genus Warileya (Hertig, 1948) includes six species, which are mainly found in the Neotropical ecozone.

Genus Brumptomyia (Franca and Parrot, 1921) comprises approximately 24 species, which are broadly distributed in Central and South America. None of these species are known to bite humans. Brumptomyia species constitute a group of sandflies commonly associated with armadillo burrows and sometimes tree trunks. The specific identification of species belonging to this genus is based entirely on male structures $[3,54,55]$.

Sandflies from the New World are present only in Nearctic and Neotropical ecozones:

1. The Nearctic region: only 14 species, a majority of which come from the Micropygomyia subgenus, are present in the Nearctic, but five are restricted to this ecozone. Most of these species exhibit a preference for hot temperatures and humidity. The temperate climate found in the Nearctic is unfavourable for phlebotomine development, particularly for immature stages. This characteristic supports the idea that phlebotomine sandflies might have originated in the tropics, with only a few species dispersing into temperate regions. The sandfly species that are currently found in North America likely arose from the Palaearctic or from South America during the arid phase in the Tertiary period. Therefore, their decreased presence may be a consequence of the constant climatic fluctuations that have occurred during the Quaternary period, causing many sandfly species to become extinct or displaced into the tropics, where hotter and more humid conditions are present $[3,56,57]$.

2. The Neotropical region: approximately 450 sandfly species are found in this ecozone. The distribution centre of the present-day Lutzomyia genus in the Neotropics is thought to be the forested lowlands present in the east of the Andes. This situation is probably a consequence of the dry periods that occurred during the Pleistocene that isolated conspecific populations, some of which became reproductively isolated and have colonized more humid areas present in the northern and western parts of the subcontinent [10]. The varied sandfly fauna present in wet areas includes many potential sandflies that feed on the blood of human beings. However, only a few are endophilic species (Colombia [58], Ecuador [59], Costa Rica [60], Peru [61], Brazil [62], French Guiana [63], Venezuela [3,8,55,64-67]).

\section{Sandfly Fossil Evidence}

Fossils, including the remains of living organisms from the past, are one of the best forms of evolutionary evidence. They allow for comparisons with current organisms and are of particular importance in allowing knowledge of primitive character states (plesiomorphic) and derived specialized states (apomorphic) to be obtained. Fossils provide information about the 
origin of vector flies in relation to infectious agents, host coevolution, and geographic locations. Therefore, research on sandfly fossils is of great importance for highlighting the evolution and phylogeny of these insects. As mentioned above, phlebotomine sandflies are found in a wide range of ecozones, which could be due to their long evolutionary history with their origins in the Palaeozoic or Mesozoic eras [68].

Arthropods first arose towards the end of the Precambrian period, approximately $550 \mathrm{mil}-$ lion years ago (MYA). The first Parainsecta appeared in the Devonian (408 MYA), and the earliest insect orders emerged during the subsequent Carboniferous period. Variegation continued to occur in the Permian (286 MYA), which was the period during which the Diptera arose. Psychodidae emerged later, during either the Jurassic [69] or the Triassic period [70]. This group was likely well diversified by the Cretaceous, and the majority of these species were likely to have been blood feeders. These observations together support the theory of a hypothetical phlebotomine-like ancestor for Psychodidae [9]. The sandflies most likely emerged during the Carboniferous and, thus, before the mammalian hosts of Leishmania. A common ancestor for Phlebotominae is thought to have occurred in the Triassic period (248 MYA) (Table 3).

To date, sixteen fossils representative of New World species have been described (15 from Dominican and one from Mexican amber). These fossils correspond to the Lutzomyia genus, including subgenera of Lutzomyia (one sp.), Micropygomyia (two spp.), Pintomyia (12 spp.), and Psathyromyia (one sp.) [71]. Additionally, some old amberic records of phlebotomine-like species have been recorded from the Old World, including some fossils deposited in France [72], Germany [73], Spain [74], Burma [75], and Lebanon [76], although the taxonomic placement of some of these species into the Phlebotominae is still unclear. The oldest known species of Phlebotominae are Phlebotomites longifilis (Hennig, 1972), P. brevifilis (Hennig, 1972), Mesophlebotomites hennigi (Azar, Solignac, Paicheler, and Bouchet, 1999), and Libanophlebotomus lutfallahi (Azar, Solignac, Paicheler, and Bouchet, 1999), for which there are fossil records described from Lebanon, in the south of the Tethys Sea, dated to approximately 120 MYA $[5,9]$. Since that time, the evolution of the Phlebotominae was likely to have been driven by major tectonic events and related climatic changes that affected the break up of Pangaea. Prior to 120 MYA, the Phlebotominae had likely remained on Pangaea for quite some time, from which separated sandfly faunas could have developed in the Old World and New World [5]. Sandfly fossil records as well as data on systematics strongly indicate that the current genera existed quite some time before the Mesozoic, 250 MYA [73]. Palaeomyia burmitis was found in Burmese amber dated from the Cretaceous period (100 MYA). Trypanosomatids associated with a fungal food source were discovered in the alimentary tract of sandfly larva. Another sandfly fossil, $P$. (Phlebotomiella) tipuliformis (Meunier, 1905), was found in Baltic amber dated from the Eocene (20 MYA). This species may have lived in the forest and fed on thin-skinned reptiles [9,77]. Sergentomyia succini (Stuckenberg, 1975), is another sandfly fossil found in Baltic amber [77]. Additionally, Phlebotomus pungens (Loew, 1845), and P. khludae (Kaddumi, 2005) [78], reported from the Old World, both were discovered in Jordanian fossil amber. Sandflies from Mexican ambers from Chiapas were identified as Micropygomyia patterna (= Lutzomyia paterna [Quate, 1963]) and dated to the Miocene (20 MYA). This species is the first known phlebotomine among the current reptile-feeding species to exhibit narrow wings and to feed on blood [9,79]. A sandfly fossil found in Dominican amber was identified as a female of Lutzomyia adiketis and was dated to approximately 20 MYA. This discovery supports the hypothesis of the radiation of Lutzomyia species throughout the Neotropics. In addition to Lutzomyia adiketis, Pintomyia falcaorum, Trichopygomyia killickorum, L. filipalpis, L. succini, L. miocena, L. paleopestis, L. schleei, P. brazilorum, P. paleotownsendi, P. paleotrichia, and M. brandao $i$ were also found in this Miocene Dominican amber. Two other groups of fossils were found 


\section{PLOS $\mid \begin{aligned} & \text { NEGLECED } \\ & \text { IROPICLL DISEASES }\end{aligned}$}

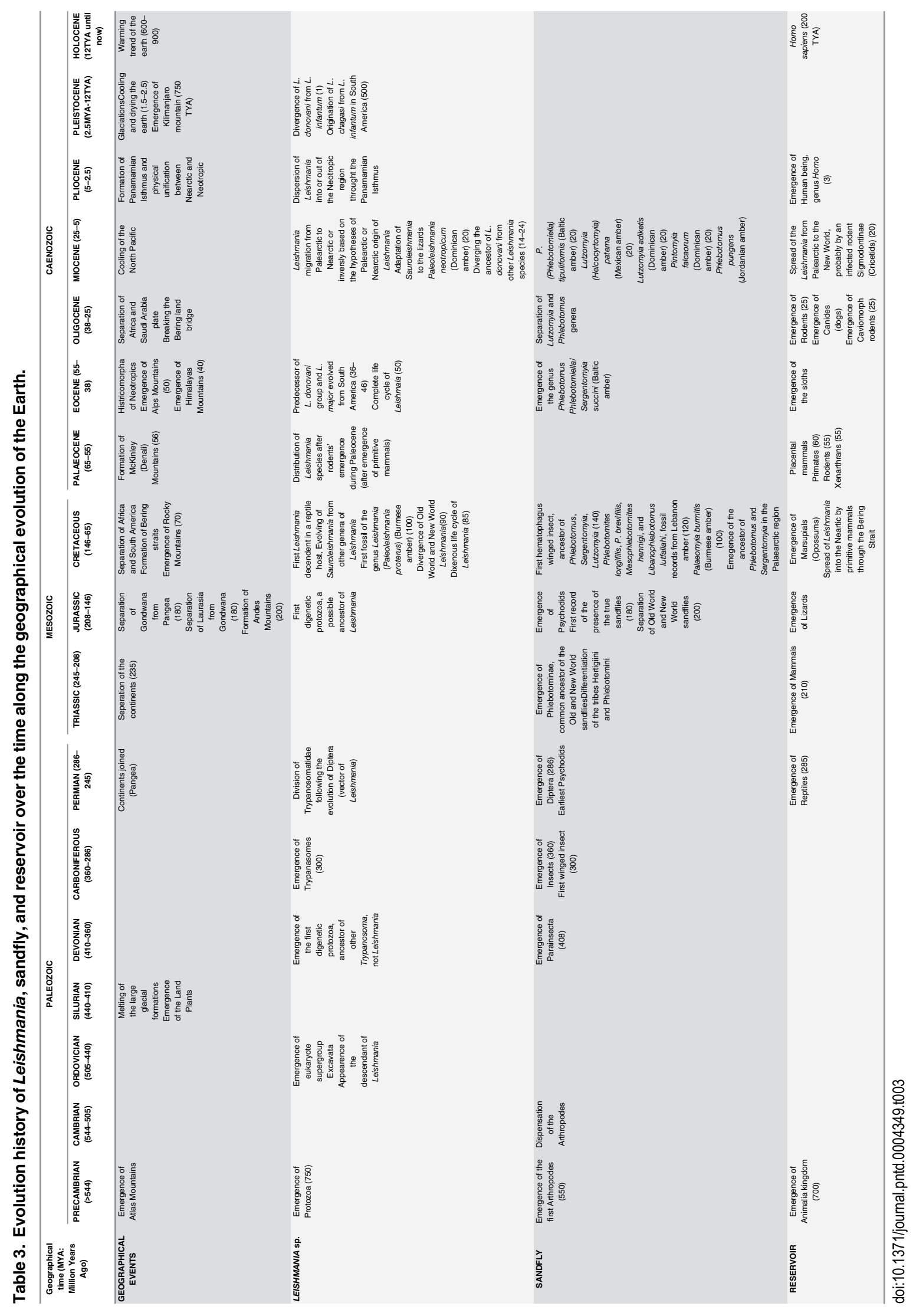


by Young and Lawyer [56] and Antoine et al. [80] in Dominican (14 specimens) and Peruvian (one specimen) ambers, dating from the Miocene. These specimens were not described by the authors that discovered the ambers.

Currently, there are two hypotheses that attempt to explain how the worldwide dispersion of sandfly ancestors occurred. The first hypothesis assumes that sandflies evolved in the Palaearctic ecozone during the Cretaceous period and were then isolated because of the breakup of Pangaea and underwent independent evolution, resulting in two subgenera, Phlebotomus (that has evolved during the Eocene) and Lutzomyia (which evolved during the Oligocene, after the breaking of the Bering bridge). These two genera include species that are involved in the transmission of Leishmania in the Old and New Worlds, respectively [81,82]. According to the second hypothesis, the similarities between the current sandfly taxa and those recorded in fossils, as well as their external positions on phenetic or cladistic trees, support the hypothesis that they existed in Gondwana before the continental separation [83].

\section{Leishmania}

The Trypanosomatidae family consists of three dixenous genera (life cycle in vertebrates or plants and invertebrates) - Trypanosoma, Phytomonas, and Leishmania-11 monoxenous genera (life cycle in invertebrates only) -Leptomonas, Crithidia (together with Leishmania form the subfamily Leishmaniinae), Blastocrithidia, Herpetomonas, Sergeia, Wallacemonas, Blechomonas, and Jaenimonas - and three genera that are characterized by the presence of endosymbiotic bacteria and form the subfamily Strigomonadinae: Angomonas, Strigomonas, and Kentomonas [84-88].

Leishmania parasites belong to the Kingdom Protista (Haeckel, 1866), Class Kinetoplastea (Honigberg, 1963 emend. Vickerman, 1976), Subclass Metakinetoplastina (Vickerman, 2004), Order Trypanosomatida (Kent, 1880), Family Trypanosomatidae (Döflein, 1901), Subfamily Leishmaniinae (Maslov and Lukeš 2012), and Genus Leishmania (Ross, 1903).

Leishmania species are heteroxenous, meaning that they are able to colonize two hosts. They live in the phagocytes of the reticulo-endothelial system of mammals and in the intestinal tract of phlebotomine sandflies, although Forcipomyia spp. (Diptera: Ceratopogonidae) as well as some tick species have been reported as the potential vectors of Leishmania sp. [89-91]. Mammalian Leishmania species exhibit a worldwide distribution (Table 4). They are present in tropical and subtropical areas, including North, Central, and South America, as well as in the Mediterranean basin, Southeast Europe, the Middle East, Central and Southeast Asia, the Indian subcontinent, Africa, and recent reports also demonstrate their presence in Australia (Table 4). In the Malagasy region, with the exception of one case of canine leishmaniasis reported by Buck et al. [92], no autochthonous case of leishmaniasis has been reported. Alvar et al. [2] presented an overview of the occurrence of leishmaniasis and causative species in all affected countries. In the Old World, most Leishmania transmissions occur peridomestically in semiarid areas modified by humans, whereas New World parasites are often associated with sylvatic habitats, though some species exhibit predominantly peridomestic transmission. Host preference is also a major factor that affects the modality of Leishmania transmission by a vector that can occur among wild animals, from animals to man, or among people. Although predominantly gut-dwelling, Leishmania parasites were rarely detected also in salivary glands of sand flies. The presence of parasites in the glands was correlated with heavy infections of metacyclic promastigotes in the stomodaeal valve and thoracic midgut of the fly. Therefore, there was a strong correlation between infected glands and the intensity of infection in the midgut, linked to the presence of numerous metacyclic forms [93]. 


\section{PLOS $\mid \begin{aligned} & \text { NEGLECTED } \\ & \text { IROPICAL DISEASES }\end{aligned}$}

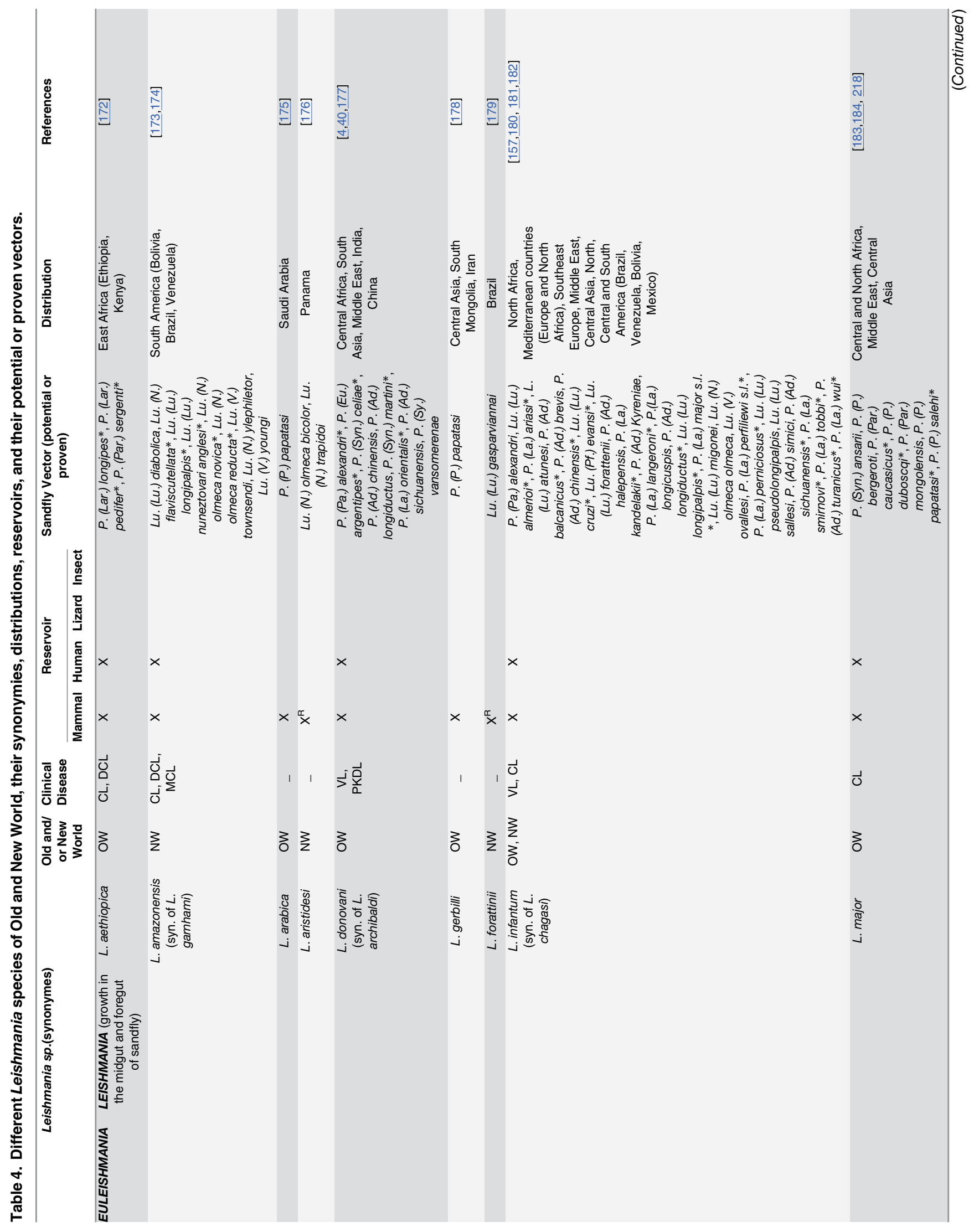




\section{PLOS $\mid \begin{aligned} & \text { NEGLECED } \\ & \text { IROPICLL DISEASES }\end{aligned}$}

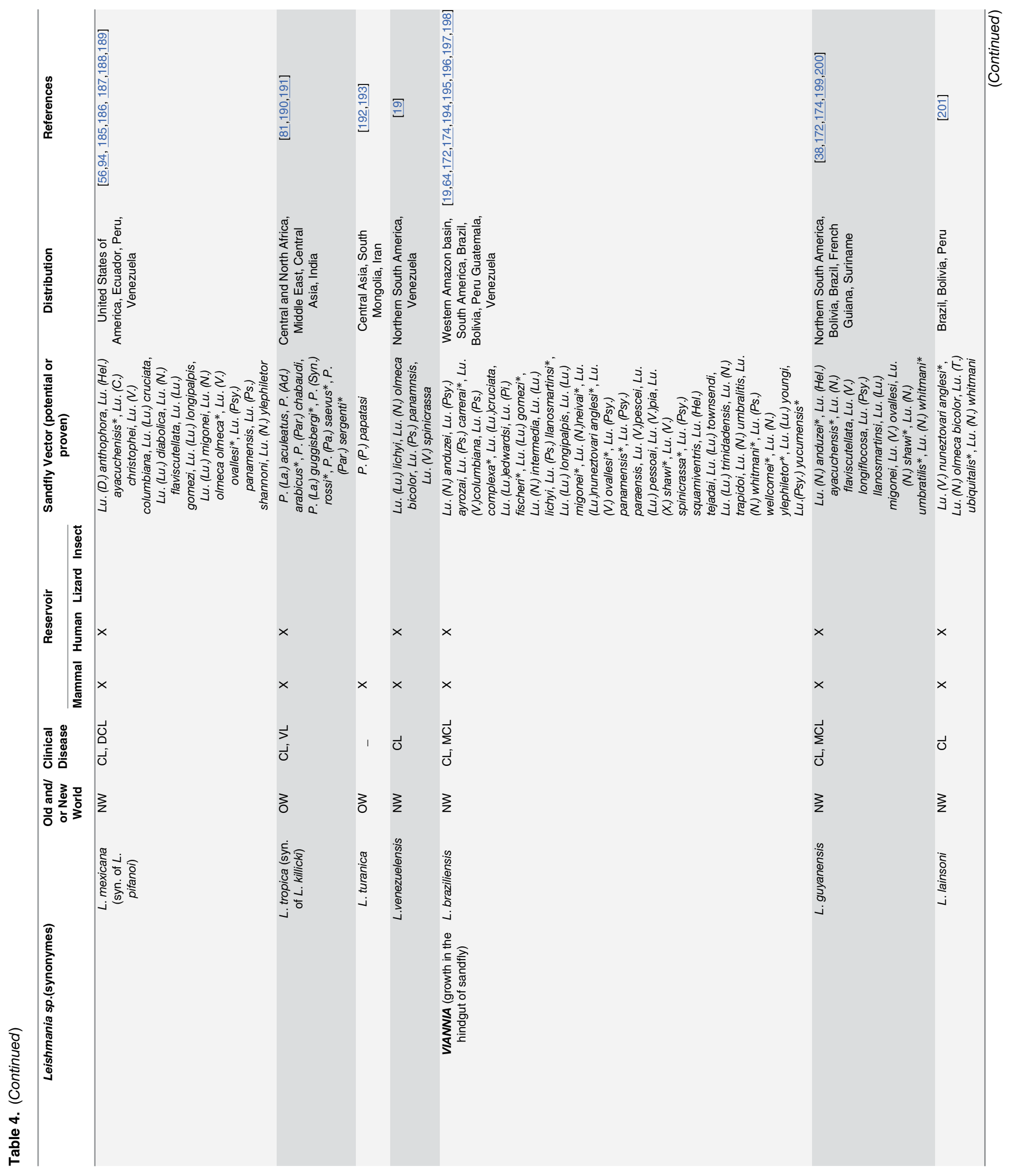




\section{PLOS $\mid \begin{gathered}\text { NEGLECTED } \\ \text { TROPICAL DISEAES }\end{gathered}$}

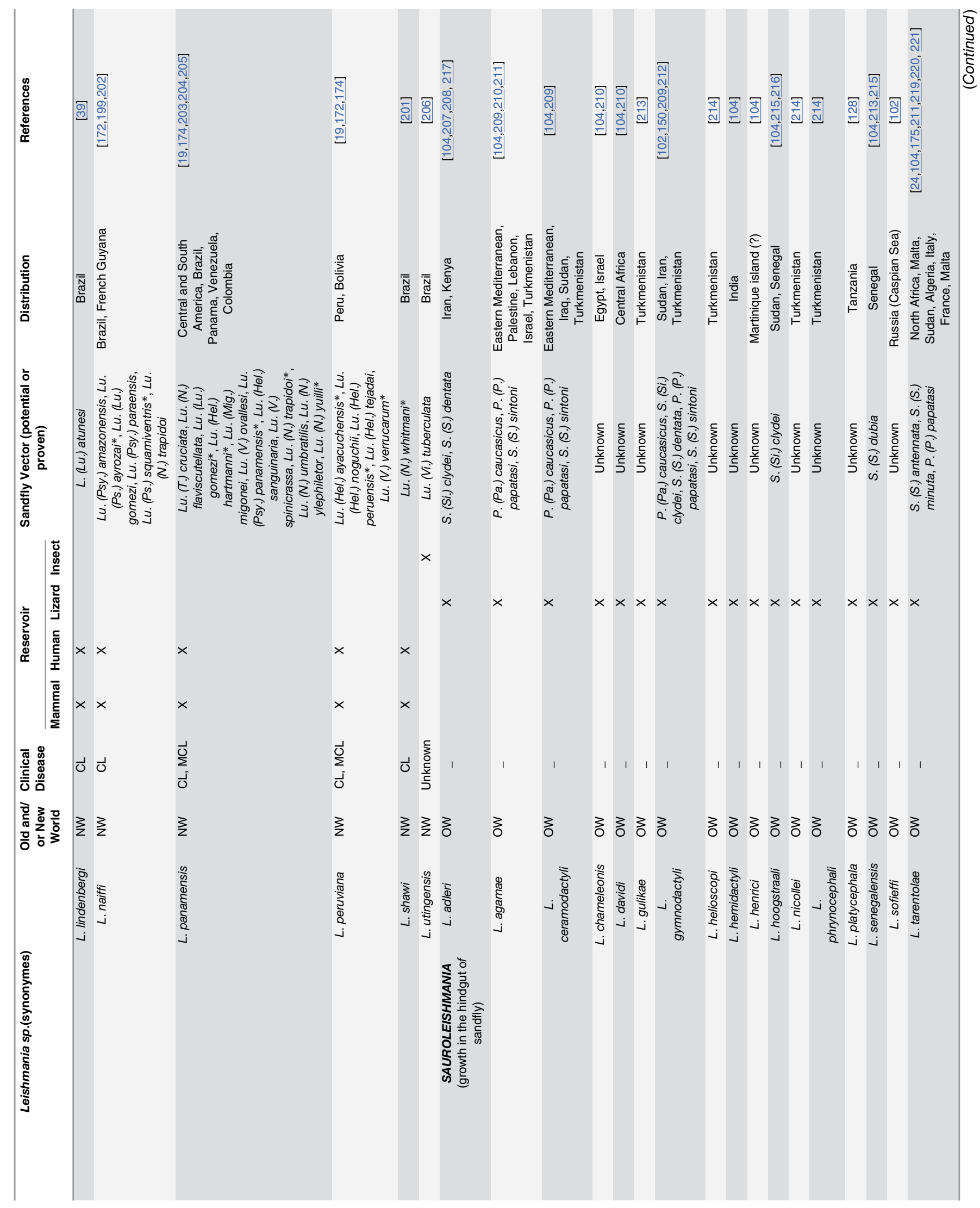




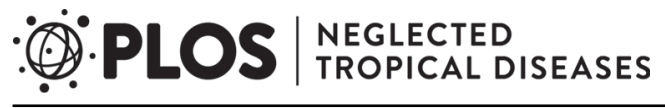

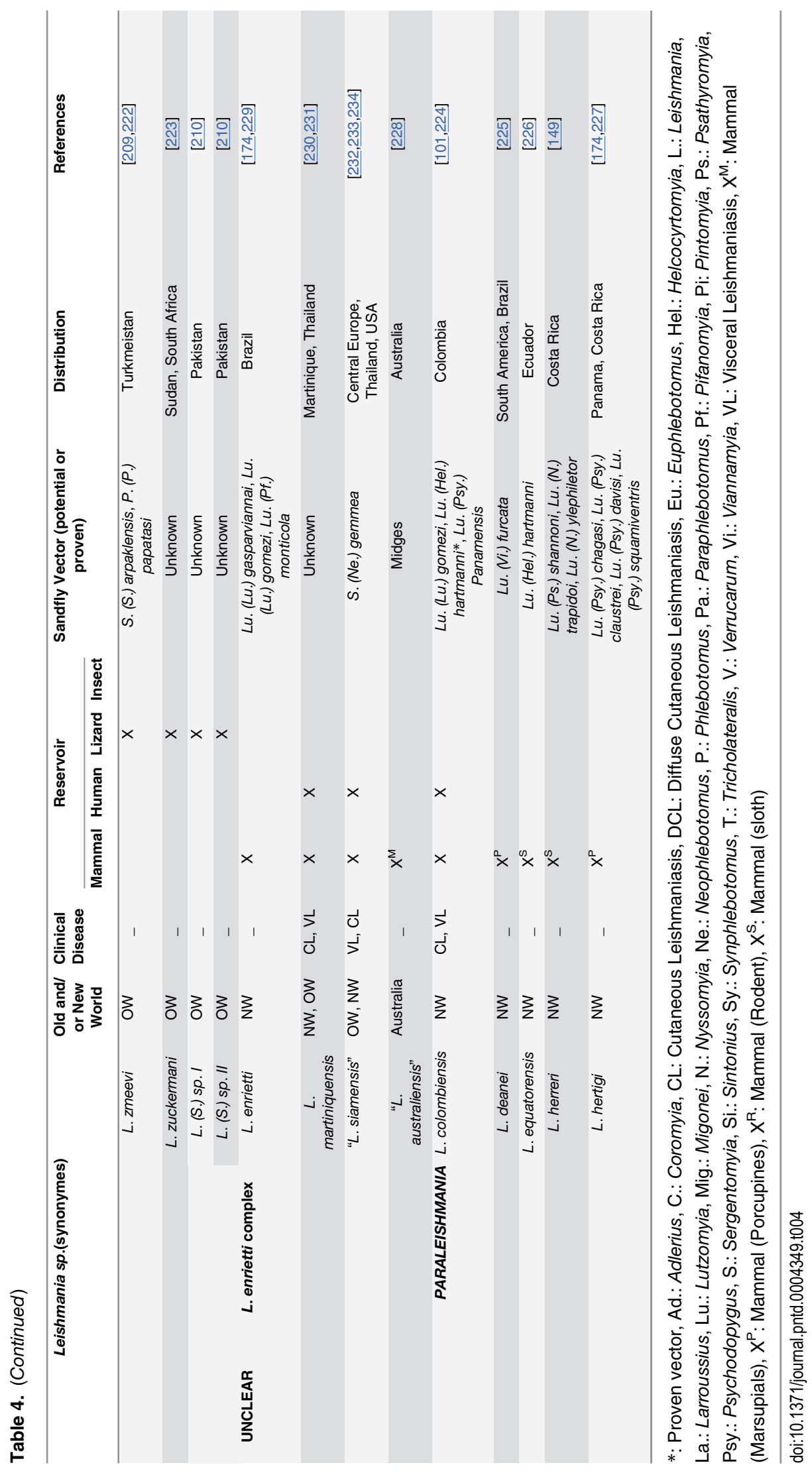


First attempts at the classification of Leishmania were monothetic Linnean classifications that were proposed between 1916 and 1961, based on extrinsic characters only (Table 1). An early Leishmania classification was suggested by Nicolle in 1908, which separated L. infantum, the etiological agent of Mediterranean visceral leishmaniasis, from L. donovani, the causative agent of Indian kala azar. Then, Biagi proposed the separation of various New World Leishmania species [94] (see Table 1). In 1964 [95], Adler discussed the difficulties in accepting a clinically based taxonomy, as leishmaniasis may demonstrate the same clinical symptoms but by two different Leishmania species, e.g., visceral leishmaniasis with cutaneous symptoms. The most intensive and extensive investigations on these parasites were carried out in the Turkmenian USSR (reviewed by Belova, [96]). Other attempts to classify mammalian Leishmania in the traditional way (that is, by naming and defining species and subspecies) were presented by Lainson and Shaw [97,98] and Bray et al. [99]. In 1976 [100], Vickerman proposed the recognition of four species complexes within the genus: the donovani complex, the tropica complex, the mexicana complex and the braziliensis complex (adapted later partially by Lainson and Shaw). In 1979 [101], Lainson and colleagues described three sections of Leishmania, according to the intravectorial development of the parasite: Hypopylaria (saurian Leishmania developing in the hindgut), Peripylaria (developing in the hindgut and pylorus), and Suprapylaria (all development anterior to the pylorus). In 1982 [102], the Russian researcher Saf janova proposed separation of Leishmania infecting lizards from other Leishmania species that infect mammals, and she proposed the name Sauroleishmania for these species [103]. The saurian Leishmania species were then assigned to a separate genus Sauroleishmania by Killick-Kendrick et al. [104]. A milestone for Leishmania classification was the system presented by Lainson and Shaw in 1987, who divided the genus Leishmania into two subgenera, L. (Leishmania) for the section Suprapylaria and L. (Viannia) for the section Peripylaria. In the early 1970s, intrinsic characteristics (immunological, biochemical, and molecular) of Leishmania were identified and used to develop new classification systems. Isoenzyme electrophoresis, developed in the 1970s, has been widely used as a typing system and was accepted over decades as the gold standard for identification and is still a valuable tool as a reference technique for parasite characterization. Since the 1980s, Adansonian phenetic classification, based on the multiple similarity-weighted characters (absence of hierarchy) applied simultaneously (polythetic classification) without an a priori hypothesis, has been employed for Leishmania classification. Subsequently, phylogenetic analyses revealed a parental relationship between different species of Leishmania. The phenetic and, especially, the cladistic classification confirmed the majority of the taxonomic groups previously established through Linnean classifications, particularly that of Lainson and Shaw [19]. Pioneering phenetic classifications based on izoenzymes have been proposed by Moreno et al. [105], Thomas-Soccol et al. [106], and Cupolillo et al. [107] for the New World and by Lanotte et al. [108] and Le Blanq et al. [109] for the Old World. Rioux et al. [110] combined all New and Old World taxa in one classification system. Several of these authors also applied a phylogenetic concept of classification [111] that is based on the concepts of monophyletism, parsimony of changes, and nonconvergence of characters [106,112]. The concordance between these classifications mutually validated both the extrinsic (geographic distribution, associated clinical syndrome, and developmental features in the sandfly gut) and intrinsic (biochemical, immunological, and molecular markers) identification criteria applied. However, cladistic analyses allowed a more detailed analysis of some groups and led to the establishment of some new complexes of species (L. infantum, L. turanica, L. guyanensis). However, some of these complexes were later rejected by molecular data. In addition, these cladistic analyses led to the proposal to place previously separated species in the same complex (L. guyanensis, L. panamensis, L. shawi) [113]. 
Recently, a new classification for Leishmania has been proposed based on combined molecular data, which divides Leishmania species into two major phylogenetic lineages referred to as sections Euleishmania and Paraleishmania [114]. The section Euleishmania comprises four subgenera: Leishmania (type strain: L. donovani), Viannia (type strain: L. braziliensis), Sauroleishmania (type strain: $L$. tarentolae), and L. enriettii complex (type strain: $L$. enriettii). Section Paraleishmania includes L. hertigi, L. deanei, L. herreri, L. equatorensis, and L. colombiensis as well as the former Endotrypanum genus. Of this group, only L. colombiensis was found to be pathogenic to humans. The evolutionary history of the section Paraleishmania has not been yet resolved, and it is so far a polyphyletic clade within the genus Leishmania. Based on izoenzyme data, the genus Leishmania was shown to be monophyletic, but inference of its origin and evolution is complicated by its disjunct geographic distribution [106]. Especially with respect to the position of Endotrypanum, with its intraerythrocyte developmental stage as well as distinct morphology (epimastigote or trypomastigote form) within section Paraleishmania, as shown by molecular data, this remains questionable and has to be carefully reevaluated. The subgenus Viannia is restricted to the Neotropics, while the subgenus Leishmania occurs in both the New and Old World. Fifty-three named species (without synonyms, including all five subgenera and complexes: Leishmania, Viannia, Sauroleishmania, L. enrittii complex, and Paraleishmania) are recognized, 29 of which are present in the Old World, 20 in the New World, three species ("L. siamensis," L. martiniquensis, and L. infantum) in both Old and New World, and one species in Australia ("L. australiensis"). Among these recognized species, 20 (without synonyms) are known to infect humans (updated information from Maroli et al. [39]).

Synonymy was shown for several species using molecular typing, e.g., L. tropica (syn. L. killicki) $[117,118,119]$ and L. donovani (syn. L. archibaldi) $[120,121,122]$. Synonymy was also suggested for L. mexicana (syn. L. pifanoi) and L. amazonensis (syn. L. garnhami). However, in all published studies, only a few representatives for these synonyms have been included, and they should be studied using an adequate sampling strategy. It was also shown by multilocus microsatellite typing (MLMT) that one species (L. infantum/L. chagasi) was only recently (ca. 500 years ago) brought from the Old World (namely Portugal) to the New World and that it found a suitable vector there $[123,124]$. For a number of species, the phylogenetic status is not yet resolved (species or subspecies or even synonyms), mainly because of the limited number of included isolates, e.g., for L. amazonensis, L. garnhami, L. pifanoi, L. venezuelensis, L. aristidesi, L. forattinii, L. arabica, L. utingensis (represented by only a single sample), L. lindenbergi, $L$. enrietti, and those belonging to the Paraleishmania section. Moreover, molecular data based mainly on $h s p 70$ [125] proved the existence of only nine monophyletic groups. These groups might represent distinct species, and several other species should be treated as subspecies within these main groups, which was also confirmed by MLMT studies, e.g., for L. braziliensis and $L$. peruviana as subspecies, $L$. donovani and $L$. infantum as subspecies, L. guyanensis, $L$. shawi, and L. panamensis as subspecies, L. mexicana and L. amazonensis as subspecies, $L$. tropica and L. aethiopica as subspecies, etc. [126]. However, not all known species have been included in these studies, especially for the L. mexicana complex.

In conclusion, molecular data based on sequences of different targets and on MLMT do not support the concept of species complexes presented by Lainson and Shaw [19,127], and the classification should be revised, including both suppression of several species and also downgrading some species to the level of subspecies. Ongoing whole-genome sequencing and SNP analysis as well as further analysis by multilocus sequence typing (MLST) and MLMT and an adequate sampling and inclusion of representatives of all species (with sufficient numbers of isolates from different areas of distribution) will contribute to further improvement of the classification of the Leishmania genus. 
Sauroleishmania was originally described by Ranque in 1973 [103] as a separate genus. It includes 19 named and two unnamed species (L. [S.] sp. I, L. [S.] sp. II; Telford [210]), according to Ovezmukhammedov and Saf janova [213], Killick-Kendrick et al. [104], and Telford [128], without specifying their taxonomic positions. Among these, ten species were considered as valid by Ovezmukhammedov and Saf janova (Fig 1) [213]. They [213] also reported one species as $L$. (S.) sp. without any additional information about its descriptor (author) and taxonomic position. During the 1980s, Leishmania that infect lizards were placed in a new genus, Sauroleishmania, which was also primarily based on the use of extrinsic characters [104]. In 1986 [129], Saf janova proposed that Leishmania species diverged from Leptomonas and that such parasites were present in primitive sandflies during the Mesozoic period. This idea was supported later by molecular data $[85,130]$. The two subgenera that encompass Leishmania infecting mammals were regarded as having been separated by continental drift during the Mesozoic, and it was suggested that Sauroleishmania developed only in the Old World because the presence of the sandfly vectors for these parasites is strictly restricted to the Old World [129].

The L. enriettii complex and related parasites form a well-supported monophyletic group (L. enriettii complex) that most likely represents a new subgenus (Pothirat et al. [115]; Kwakye-Nuako et al. [116]). The only two formally described and named members of this group are L. enriettii, described in 1948 and repeatedly isolated from domestic guinea pigs, and Leishmania martiniquensis, described in 2014 as a causative agent of human diseases. Another three members that have been accommodated into the L. enriettii complex are: (i) never formally described "L. siamensis" from human patients; (ii) unnamed species sometimes called "L. australiensis" from Australia marsupials, most likely transmitted by midges; and (iii) very recently (2015) introduced unnamed Leishmania species from human cases in Ghana. At the moment, the names of "L. siamensis" and "L. australiensis" are not taxonomically valid names. For this, these names have been used in this paper with quotation marks.

The Endotrypanum genus belonging to the Paraleishmania group is known as a parasite of sloths that is transmitted by Lutzomyia species in Central and South America. These parasites are found within the erythrocytes of the Choloepus and Bradypus sloth genera. Only two species, Endotrypanum schaudinni and E. monterogeii, have been described in this genus [131]. The parasites that have been obtained through the in vitro culture of infected blood from sloths and from Lutzomyia sandfly guts are promastigotes that are indistinguishable from Leishmania promastigotes. Sloths also serve as a reservoir of L. braziliensis, L. guyanensis, L. herreri, $L$. equatoriensis, and L. panamensis, which are transmitted by sandfly vectors. They could be one of the first vertebrate hosts in which the dixenous life cycle of Leishmania could have emerged.

\section{Leishmania Fossil Evidence}

Leishmania belongs to the phylum Kinetoplastida, which is likely related to the phylum of Euglenids [132]. Both of these groups belong to the eukaryotic supergroup Excavata, for which fossil evidence suggests emergence during the Ordovician [133]. Leishmania might have originated during the Mesozoic, prior to the separation of Gondwana [106]. The first Leishmania fossil record was Paleoleishmania proterus, a digenetic Leishmania species associated with a blood-filled female of the sandfly P. burmitis in Burmese fossil amber (Cretaceous, 100 MYA) (Table 3) [134]. Within the alimentary canal of this sandfly, amastigotes $(n=20)$, promastigotes $(n=393)$, and paramastigotes $(n=64)$ of digenetic leishmanial trypanosomatids were observed. The observation of these different parasitic stages in the alimentary tract of the insect suggests that their presence was likely the result of a blood meal and that they were multiplying within the midgut. The blood cells were later identified as being of reptilian origin. They also 
described the development of putative amastigotes within whitish, spherical-to-oval vacuoles associated with some blood cells. The second fossil of Paleoleishmania species described was $P$. neotropicum, which was found in Dominican fossil amber (20 MYA). A large number of promastigotes $(n=20)$ and amastigotes $(n=20)$ were found in the gut of L. adiketis. Additionally, four promastigotes, two paramastigotes, and several amastigotes of $P$. neotropicum were found in the proboscis of L. adiketis. The presence of amastigotes demonstrated the digenetic life cycle of $P$. neotropicum, as this parasitic life stage is considered to be present only in the vertebrate host, and no monogenetic flagellates are known to colonize sandflies.

The kingdom Animalia appeared 700 MYA, and the first Leishmania host ancestor likely also appeared at this time. In this period, the Earth was covered by water with a lower oxygen concentration [135]. The definitive hosts for primitive Leishmania may therefore have been reptiles or primitive mammals. It was initially suggested that the Leishmania genus originated in the Palaeocene, following the emergence of the first placental mammals. The ancestors of Leishmania emerged during the Ordovician $[130,136]$, while winged insects appeared during the Carboniferous (300 MYA), and the first hematophagous winged insect appeared during the Cretaceous (140 MYA) [137]. The separation between primitive Phlebotomus and Lutzomyia arose approximately 200 MYA [138]. While trypanosomatids were present during the Palaeozoic, free-living forms were likely more diverse in the past than today. In this period, the Leishmania ancestor was separated into Sauroleishmania (reptile-infecting Leishmania) and the current Leishmania genus (mammal-infecting Leishmania) [139]. Subsequently, the division of Leishmania into L. (Leishmania) and L. (Viannia) occurred approximately between 54 to 25 MYA, after the separation of Africa from South America [140]. Geologically, the Earth experienced a cooling and drying period (1.5-2.5 MYA). The grassland biomes required for the development of the earliest murid rodents likely shifted towards the equator and the tropical forest biomes [141]. Along with their required biome, sigmodontine rodents (Rodentia: Muridae: Sigmodontinae) travelled across the Panamanian land bridge into South America.

The observation of sandfly larvae that develop in habitats containing trypanosomatid flagellates led to the hypothesis that sandflies host monoxenous trypanosomatids, and that these flagellates were carried through the pupal into the adult stage. This corresponds with the fact that Leishmania parasites evolved originally from Leptomonas monoxenous trypanosomatids [85], which are rarely transmitted to mammalian hosts, including humans [130]. The transmission of flagellates by an adult sandfly to a vertebrate host, establishing a continuing cycle between the vector and vertebrate species, likely occurred before the appearance of placental mammals during the Palaeocene. Thus, the appearance of placental mammals appears to have occurred after the appearance of the currently known Leishmania vectors, i.e., Phlebotomus and Lutzomyia species. Hence, the vector, mammalian host, and fossil record all suggest that leishmaniasis may have been established during the Palaeocene (65-31 MYA).

\section{Palaearctic Origin of Leishmania}

A Palaearctic origin of the genus Leishmania was proposed by Lysenko in 1971 [142]. Fossil evidence indicates that both phlebotomine sandflies and murid rodents originated in the Palaearctic $[5,143]$, making it likely that Leishmania, along with its vectors and reservoirs, could have evolved in the Palaearctic during the Cenozoic period and dispersed to the Nearctic during the Oligocene (Eocene), when the Bering land bridge was intact. These species then dispersed into the Neotropics across the Panamanian land bridge during the Pliocene, when the climate was sufficiently warm to permit further dispersal of Leishmania (Fig 2) [82,142,144,145].

Molecular analyses of Leishmania strains coming from various Old World endemic areas suggest that $L$. donovani and $L$. infantum, which are responsible for VL, likely diverged 


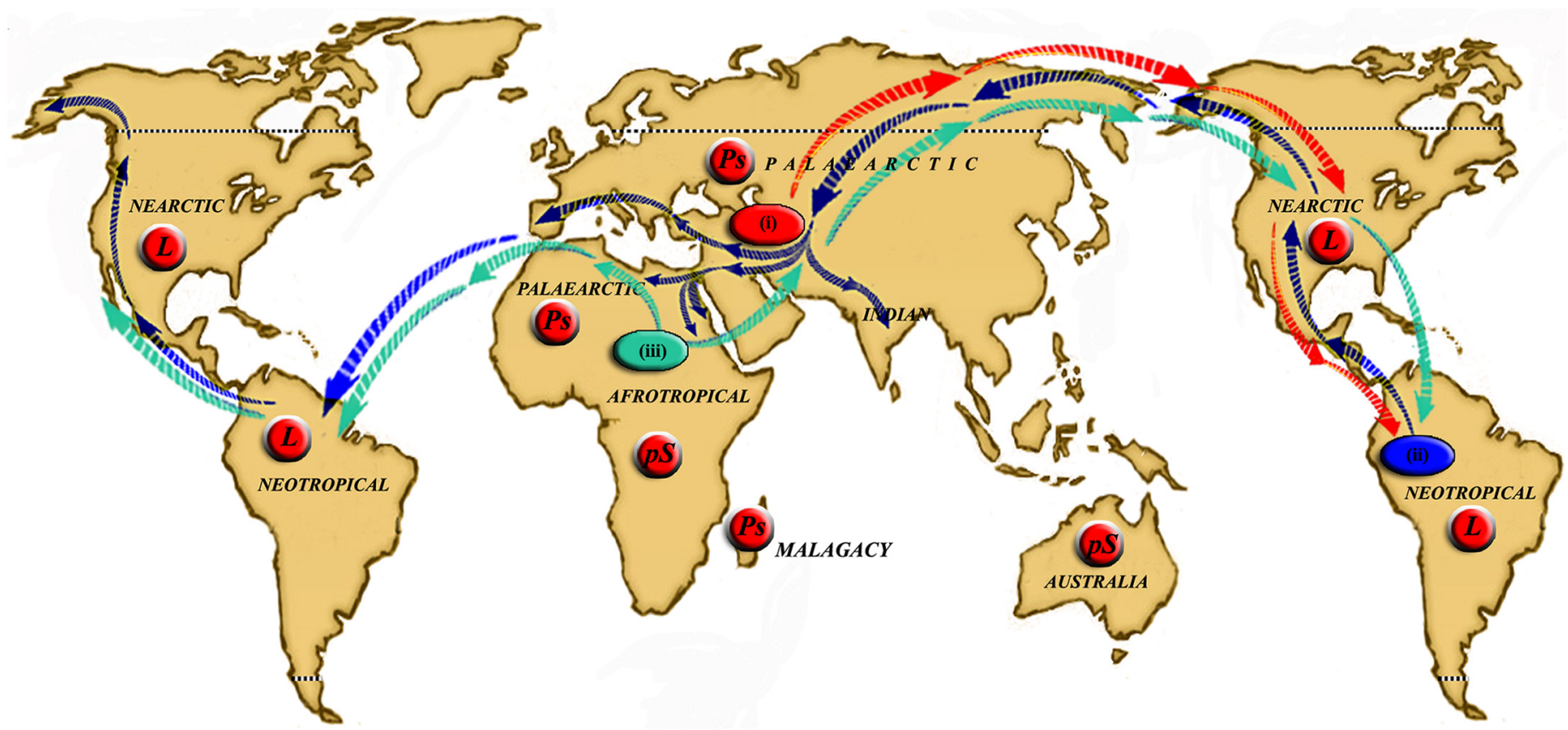

Fig 2. Possible routes of dissemination of Leishmania. (i). Red arrow: Palearctic origin of Leishmania (Lysenko [142], Kerr [136,144], Kerr et al. [145]). (ii) Blue arrow: Neotropical origin of Leishmania (Croan et al. [150], Noyes [149], Noyes et al. [83], Lukeš et al. [146]). (iii) Green arrow: Neotropical/African origin of Leishmania (Momen and Cupolillo [139]). Distribution of medically important sandflies is highlighted by red symbols. L: Lutzomyia, P: Phlebotomus, S: Sergentomyia, PS: Relative density and diversity of Phlebotomus as compared to Sergentomyia.

doi:10.1371/journal.pntd.0004349.g002 
phlebotomine sandfly ancestor evolved in the Palaearctic (Cretaceous, 120 MYA) and that Phlebotomus also evolved in the Palaearctic (Eocene, Baltic amber), and Lutzomyia diverged from Phlebotomus (Oligocene, Mexican amber) after the breaking of the Bering land bridge $[136,141,145]$.

\section{Neotropical Origin of Leishmania}

In 1998 [149], Noyes suggested a Neotropical origin of Leishmania during the Palaeocene or Eocene period (36-46 MYA). Subsequently, the parasites invaded the Nearctic ecozone via the Panamanian land bridge and the Palaearctic via the Bering land bridge during the Miocene. The greater diversity observed among New World Leishmania species compared with those from the Old World provides some circumstantial evidence arguing for a Neotropical origin of Leishmania [19,150]. Nevertheless, if this hypothesis is true, then Sauroleishmania might have evolved later during the Miocene, either in the Nearctic or the Palaearctic area, as a result of adaptation to reptiles [149]. Sloths (Xenarthra) might have served as the first vertebrate reservoirs of Leishmania in the Neotropics. Also, it has been suggested that a number of monogenetic and digenetic trypanosomatids can grow in the rectal glands of marsupials. After adaptation to rodents during the Eocene, infected porcupines would have carried the parasites across the Panamanian land bridge to the Nearctics and across the Bering land bridge to the Palaearctic during the Miocene in an unspecified mammalian reservoir (Fig 2) $[83,149,150]$.

Climate change, in combination with the topographic diversity found in the Central and South America, has certainly played a role in the vicariance of the sigmodontine rodents and their accelerated speciation. The cricetids (sigmodontines) encompass approximately 40 genera and more than 200 species that evolved within approximately 2.5 MYA [141]. A similarly rapid rate of evolution is observed in New World Leishmania [141,151].

\section{Neotropical/African Origin of Leishmania}

According to this theory, the genus Leishmania is divided into two sections: Euleishmania (Leishmania and Viannia subgenera and Sauroleishmania) and Paraleishmania (L. hertigi, L. deanei, L. colombiensis, L. equatorensis, and L. herreri) [114,139]. It is also speculated that the separation of Gondwana in the Mesozoic resulted in the evolution of the Leishmania genus into Leishmania and Sauroleishmania in Africa, and Viannia and Paraleishmania in South America [139]. The origin and the evolution of Leishmania would have been related to the origin of humans in eastern Africa, with Leishmania following the dynamics of the human population in the Palaearctic (Asia, Africa, and Europe) ecozone. An African origin of Leishmania was emphasized by Momen and Cupolillo [139], based on the importance of the origins of its vectors and reservoirs as evidence for this hypothesis and citing the restricted habitat of Arvicanthis rodents and Phlebotomus sandflies in Africa. According to this hypothesis, the Old World Leishmania species (e.g., L. donovani/L. infantum, L. tropica, L. major, and L. aethiopica) exhibit an African origin. L. aethiopica is present only in the Ethiopian and Kenyan highlands. Because of its restricted geographical distribution, it is reasonable to assume an African origin for this species as well as for the other L. (Leishmania)-hyrax systems that occur in Africa [128]. The origin of humans from eastern Africa suggests that Leishmania species with anthroponotic transmission, i.e., L. tropica and L. donovani, may also have originated in eastern Africa (Fig 2) [152].

\section{Relationship between Sandflies and Leishmania}

The term "coevolution" was first used to demonstrate a particular type of relationship between Leishmania and sandfly species in the Old World [147]. Leishmania and sandflies have 
survived over many millions of years under selective pressure, depending on natural ecological changes. A close relationship has been demonstrated between some sandfly and Leishmania species, such as L. major and P. papatasi. This longstanding evolutionary history of Leishmania and sandflies has resulted in a similar distribution. However, there is not always a clear distinction between coevolution and certain other concepts, such as coassociation (meaning that the transmission cycle exhibits a distinctive landscape epidemiology), interaction (the molecular and immunological relationship between the sandfly midgut and the parasite's external surface), or vector-parasite cospeciation or co-cladogenesis [37]. Most Leishmania parasites are more restricted regarding the range of sandfly vectors that can transmit them than in the range of mammalian hosts/reservoirs they are able to infect, suggesting a much closer coevolutionary relationship with sandflies than with their vertebrate hosts, although it is sometimes difficult to interpret this coevolutionary relationship [153]. For example, there is a specific relationship between P. papatasi and L. major because of the presence of specific midgut receptors [154], and these two species show strong distribution sympatry. Nevertheless, such high specificity of Leishmania for its sandfly vector appears to be restricted to P. papatasi or P. duboscqi and P. sergenti. However, the appearance of Leishmania interspecies hybrids might have consequences in terms of specificity and transmission efficiency [155,156].

The incrimination of sandflies as proven or potential vectors of Leishmania is a controversial and debated matter. Five criteria stated by Killick-Kendrick [104] are required to incriminate a particular sandfly species as a vector, which include the observation of corresponding epidemiological data, feeding behaviour of the sandflies on the animal intermediate host, the isolation of promastigote parasites from the sandflies, the occurrence of the complete life cycle of the parasite in its putative vector, and experimental transmission of the parasite through the bite of the infected species. Since the 1990s, with PCR invention and advances in molecular parasitology, molecular evidence was added to the mentioned criteria, and reports regarding the presence of Leishmania DNA in various sandfly species have dramatically increased. Nevertheless, according to the above-mentioned criteria, the presence of Leishmania DNA within sandflies should certainly not be considered to be a sufficient criterion to incriminate a sandfly species as a proven vector. Further evidence highlighting the presence of metacyclic promastigotes within the insect's gut as well as demonstration of the insect's capacity to retransmit Leishmania are essential criteria that need to be investigated to indicate the vectorial competence of sandflies. Approximately 166 species have been reported to be proven or potential vectors of different Leishmania species in the Old and New World (Table 4). Among these species, 78 are reported as the proven vectors of Leishmania. In the Old World, Leishmania are transmitted by sandflies belonging to the Phlebotomus genus ( 49 species, 31 are reported as proven), while Sauroleishmania are transmitted by sandflies of the Sergentomyia genus. In the New World, Leishmania, Viannia, and Endotrypanum species are transmitted by sandflies belonging to the Lutzomyia genus (118 species, 47 are reported as proven). Among the above-mentioned sandfly vectors, seven are involved in the transmission of $L$. major, seven in the transmission of L. tropica, 31 in the transmission of L. infantum, and nine in the transmission of L. donovani. New World sandflies (genus Lutzomyia) are involved in the transmission of different species (see Table 4, updated information from various publications). The stronger restriction of vectors to cutaneous Leishmania species than to vectors of either the visceralizing donovani/infantum group [147] or L. (Viannia) [19] provides support for the hypothesis that cutaneous species evolved first.

Cutaneous leishmaniasis (CL) is a vector-borne zoonotic disease, involving various wild rodents and humans as vertebrate hosts and different sandfly species as vectors playing a role in Leishmania transmission. In the Old World, a large majority of CL cases are geographically restricted to the arid and semiarid areas of the North, Central sub-Saharan, and East African 
regions; the Near East and Middle East; and Central Asia and India. New World CL occurs in tropical and subtropical areas of Mexico and Central and South America. The Leishmania species responsible for CL differ between the Old and New World. In the Old World, the etiological agents of CL include L. tropica, L. major, and L. aethiopica, whereas New World CL is caused by parasites of the L. mexicana complex (L. mexicana, L. amazonensis, L. pifanoi, $L$. garnhami, and L. venezuelensis) or the subgenus Viannia (L. braziliensis, L. guyanensis, $L$. panamensis, L. naiffi, L. shawi, L. lainsoni, and L. peruviana). In the Old World, the proven vectors of CL are mainly classified in the subgenera Phlebotomus and Paraphlebotomus, even though some species of the Adlerius and Larroussius subgenera are thought to be vectors of parasites causing Old World CL $[81,157]$. In the New World, the main vectors of CL belong to the subgenera Nyssomyia, Psychodopygus, Lutzomyia s.str., and Verrucarum (Fig 3) (Table 4).

Diffuse cutaneous leishmaniasis (DCL) was first reported in Kenya in 1969. This disease is an anergic variant of localized CL, in which lesions are disseminated. The causative agent is $L$. aethiopica, which is transmitted by $P$. pedifer and P. longipes. Nevertheless, DCL caused by $L$. amazonensis, transmitted by Lutzomyia-group Olmeca in the New World, has also been reported.

Mucocutaneous leishmaniasis (MCL), or espundia, occurs exclusively in South America, showing a greater incidence in Peru, Bolivia, Paraguay, Ecuador, Colombia, and Venezuela. $L$. braziliensis (Viannia subgenus) is the main causative agent, and to a lesser extent, L. guyanensis, L. panamensis, and L. amazonensis are also known to be responsible for MCL in this region. The vectors of this disease mainly belong to the subgenus Psychodopygus (e.g., L. (Ps.) wellcomei) [158].

Visceral leishmaniasis (VL) is usually a systemic disease that affects internal organs, particularly the spleen, liver, and bone marrow. L. donovani and L. infantum are the agents responsible for Old World VL, whereas L. chagasi (synonym with L. infantum) is responsible for New

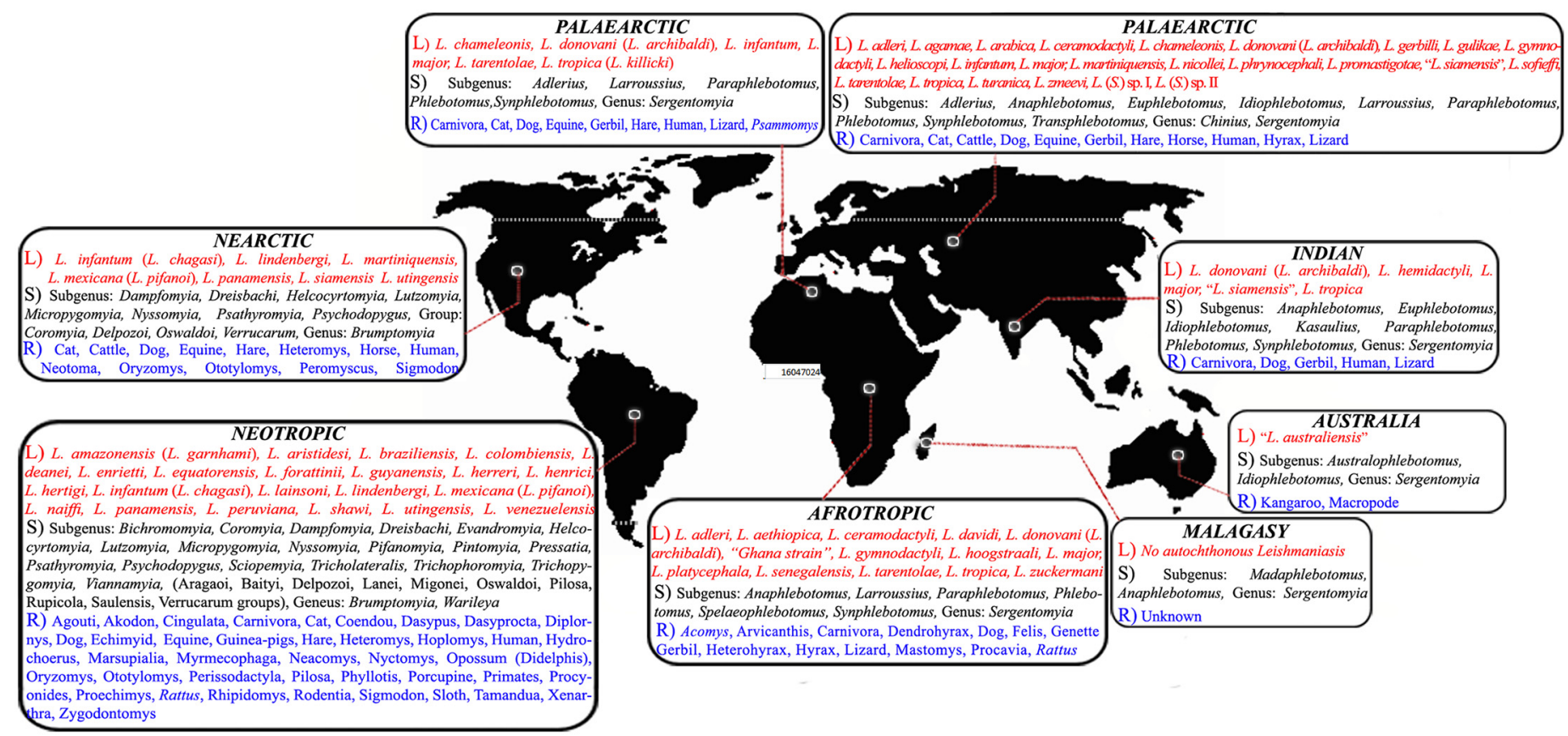

Fig 3. Geographical distributions of various Leishmania spp.; sandflies and animal reservoirs in the Old and New World. L: Leishmania (species), S: Sandfly (genus or subgenus), R: Reservoir (genus or family).

doi:10.1371/journal.pntd.0004349.g003 
World VL. Some VL cases caused by L. tropica or L. amazonensis have also been reported [159]. The main VL vectors belong to the Euphlebotomus, Larroussius, and Synphlebotomus subgenera [160], but some species of the Adlerius and Paraphlebotomus subgenera have also been reported as vectors of $L$. infantum and $L$. donovani. The vectors involved in the transmission of New World VL belong to the Lutzomyia sensu stricto, Migonemyia, Nyssomyia, Pifanomyia, Psychodopygus, and Verrucarum subgenera (Fig 3) [161].

\section{Discussion and Conclusion}

Phlebotomine sandfly systematics, particularly at the supraspecific level, have always been controversial [34,53]. Originally, this family was composed of a single genus: Phlebotomus Rondani. In 1948, Theodor proposed subdivision of the sandfly family into four genera: Phlebotomus and Sergentomyia in the Old World and Lutzomyia and Brumptomyia in the New World. A "stable" classification of the phlebotomine sandflies was proposed in 1977 by Lewis and colleagues [14], who retained the well-known family, subfamily, and genus names. It was also proposed that the subgenera and species groups be used as a model to put forward a new proposal. A "flexible" classification was proposed by Ready and colleagues in 1980 [162]. These researchers challenged the "stable" classification through a comparative analysis of characters that were described as "exclusive" characters for their proposed genera, e.g., Phlebotomus, Sergentomyia, Brumptomyia, Warileya, and Psychodopygus, but no such characters were found for Lutzomyia. The absence of unique characters for the genus Lutzomyia is certainly the weakest point in their comparative character analysis. New discoveries in later years led to the erection of new subgenera or genera. One of the difficulties in sandfly classification concerns the position of sandfly species at the genus or subgenus level. There is no general agreement regarding the definition of some groups at the genus or subgenus level. Idiophlebotomus in Phlebotomus, as well as Parrotomyia, Rondanomyia, and Grassomyia in Sergentomyia were classified by Quate and Fairchild [163] at the subgenus level, whereas Abonnenc [164] considered Idiophlebotomus to be genus and Sergentomyia to be a subgenus. Abonnenc and Minter [165] did not include Parvidens as a subgenus of Sergentomyia, whereas Abonnenc [164] considered Parvidens to be a subgenus of the Phlebotomus genus. Lewis [5] declined to recognize generic status for Spelaeophlebotomus and Idiophlebotomus, whereas Artemiev and Neronov [166] considered them at the genus level. Similarly, for New World sandfly species, Young and Duncan [8] classified Bichromomyia, Dampfomyia, Deanemyia, Evandromyia, Expapillata, Martinsmyia, Micropigomyia, Migonemyia, Nyssomyia, Pintomyia, Psathyomyia, Psychodopigus, Trichophoroymyia, Trichopigomyia, and Viannamyia to be subgenera of the Lutzomyia genus, whereas Galati et al. [66] elevated these groups to the genus level. These conflicts in classification are mainly due to (i) differences or variations in the criteria and the methods used for classification, such as criteria that are now considered to be outdated or scarce, e.g., the presence of erected or recumbent abdominal setae; (ii) morphological similarities between species and some uncertainty in species identification, such as the existence of cryptic or sibling species and the similarity of morphological characters among females that makes species identification dependent on male characters (e.g., Adlerius); (iii) the inadequacy of the reported species descriptions; and (iv) the massive increase in the number of sandfly species described. The construction of a well-supported phylogeny of the generic and subgeneric groups in the Phlebotominae subfamily will likely require a supermatrix analysis. This matrix must include molecular information on several nuclear genes combined with mitochondrial genes-as well as other criteria related to biology - and ecology, which has been successfully applied for the classification of the Drosophilidae family [167]. This type of analysis would provide a firmer basis for the classification of Phlebotominae sandflies, in addition to resolving the problem of the proposal 
of classifications suggested for the Old World and New World sandflies. Therefore, a more extensive molecular phylogenetic analysis, e.g., focussing on gene flow and the phenotypes of specimens, awaits the development of an accurate and valid protocol for sandfly classification.

A reliable taxonomy of Leishmania species will represent a keystone for biological and epidemiological research programs. There is still no universal agreement regarding the classification of Leishmania, especially concerning the criteria defined for species definition, or the method used to address phylogenetic classification. The greatest inconsistency concerns the assignment of Leishmania at the specific or subspecific level. Although the clustering of Leishmania at the subgeneric level and the definition of "complexes" in Leishmania classification have gained rather wide acceptance since being reported by Lainson and Shaw [98], there are still serious challenges in terms of the genus composition. Various molecular methods have been introduced to elucidate the taxonomy of Leishmania, though defining a Leishmania species or accepting all of the described species is still not straightforward. The currently accepted classification of Leishmania proposes the division of this genus into three subgenera: Leishmania, Viannia, and Sauroleishmania. Under this proposal, species that cannot be classified into any of these subgenera are included in the Paraleishmania section, such as yet-unclear-status Leishmania parasites. A question that remains open to debate is the position and classification of Sauroleishmania. Because this group is of low medical importance, there is little information about the reliability of its classification at present. Its placement in the Leishmania phylogeny therefore remains highly debated. Contradictorily, Kerr [144] proposed that the mammalian Leishmania evolved from lizard Sauroleishmania in the Palaearctic, whereas Noyes [149] controversially suggested that lizard Sauroleishmania evolved from mammalian parasites. This group has been placed both at the crown of the phylogeny $[83,139,150]$ and at its root $[136,144,145]$. It appears more likely that the position of Sauroleishmania external to all L. (Leishmania) is a consequence of a faster rate of evolution in this subgenus, as suggested by a molecular phylogenetic analysis performed on the RNA and DNA polymerase genes [150]. Therefore, the systematic position of many Leishmania infecting reptiles remains unresolved. This difficulty in assigning a phylogenetic position is likely due to (i) the paucity of information about the life cycle of Sauroleishmania; (ii) the fact that all of the flagellates found in reptiles have been studied mainly at the light-optical level (except some submitted sequences in Genbank), without additional study methods being applied (serological, biochemical, and others), whereas some flagellates from reptiles belong to Trypanosoma and are also transmitted by sand flies; and (iii) the existence of a priori notions that every flagellate detected in a reptile's body should be attributed to Leishmania promastigotes without further study of their true identity. Therefore, to avoid any doubt in the classification of Leishmania as well as Sauroleishmania, emphasis on the exploration of new isolates via molecular biology and phylogenetic (DNA analysis) methods is suggested. Finally, to clarify the position of Leishmania species in this classification, it is proposed that assignment to major groups across the entire genus Leishmania should be based on gene sequences, which are remarkably congruent and uncontroversial. For classification within the major groups, more highly discriminatory markers, such as MLST markers, microsatellites, or genome-wide single nucleotide polymorphisms, are considered to be better suited.

Knowledge about the origin and dispersal of Leishmania will help us to more precisely understand the factors that have and will continue to influence the circulation of leishmaniasis, in relation to its etiological parasitic agents, the vectors that transmit them, and their reservoirs. The dissemination of Leishmania has followed the migration of its vectors and hosts together [168]. Concerning the origin of Leishmania species, several hypotheses have been proposed, which were described above. These hypotheses profit from significant fossil, molecular, ecological, and biochemical data supporting them. Nevertheless, the debate is still open. To gather 
more information to support hypotheses of the origin and evolution of Leishmania, more evidence must be considered. Such evidence will include the following:

- Molecular phylogenies: based on several independent genes that display different evolutionary constraints, e.g., the elongation factor (EF-1 $\alpha$ ), heat shock protein gene ( $h s p 70)$, and glyceraldehyde dehydrogenase (GAPDH), SSU (small subunit of ribosomal DNAs), DNA Polymerase $\alpha$ (POLA), cytochrome b (cytb), cysteine proteases, RNA polymerase II large subunit, gp63, mini-exon, and internal transcribed spacer of rDNA (ITS) (at lower taxonomical level) and spliced leader (SL) genes. Some of these genes are single-copy, protein-coding genes and are therefore suitable candidates for studying the molecular systematics and phylogeny of Leishmania [169].

- Biogeographical and ecological evidence: geographical, ecological, and climatic aspects as well as geological periods of the Earth and the presence of natural environmental pressures or geographical barriers must be investigated to obtain insight into the origin, evolution, and dispersion of Leishmania. It is worth considering that the absence or emergence of geographical barriers, such as mountains, in the past few million years (or even today), has resulted in a wider or restricted distribution of Leishmania parasites and their sandfly vectors and animal hosts at a worldwide scale.

- Entomological evidence: considering that leishmaniasis is a vector-borne disease, it is of course essential to more precisely understand the origin and the evolution of sandfly vectors along with Leishmania development, considering their coevolution and sympatry in different periods of time.

- Mammalogical evidence: considering that leishmaniasis is a zoonotic disease, the origin, conservation, and dispersion of Leishmania is highly dependent on animal reservoirs.

Three hypotheses have been proposed concerning the origin of Leishmania (Fig 2). Kerr [144] proposed a Palaearctic origin of Leishmania, based on a study carried out by Lysenko in 1971 [142]. He used fossil evidence of mammalian taxa and sandflies previously reported by Nowak [143] and Lewis [5], respectively, to support his hypothesis. Nevertheless, this hypothesis has been proposed based on a biogeographical study, which must be tested against other independent datasets. In 2000 [144], based on biogeographical evidence, fossil records of mammals and sandflies, and ecological data, Kerr also proposed a revision of the Leishmanial Sauroleishmania clade, but the lack of an independent phylogenetic analysis undermined the reliability of this hypothesis. Several factors argue against a Neotropical origin of Leishmania. Based on this theory, (i) porcupines did not move from the Neotropic to the Nearctic, whereas the fossil record demonstrates that such migration occurred after the formation of the Panamanian land bridge during the Pliocene [143]; (ii) porcupines did not travel across the Bering land bridge; (iii) the use of nonmolecular evidence, such as data based on biogeography, epidemiology, ecology, and historical events, is controversial; and (iv) there is an inconsistency between the current classifications of phlebotomine sandflies and the proposed Neotropical origin of Leishmania as well as a discrepancy between a Palaearctic origin of the murid rodents and a Neotropical origin of the parasite $[7,139,144]$. The third hypothesis considers Leishmania to exhibit a Neotropical/African origin. Despite reported evidence, this theory does not consider human dispersion into the Neotropics [139]. Finally, based on this hypothesis, a serious question remains regarding the Sauroleishmania phylogeny at the crown of the phylogenic tree and the dispersal of Leishmania from Africa to the Neotropics before the separation of Pangaea when considering the lack of evidence concerning the presence of Sauroleishmania in the Neotropics. 
The question about Leishmania evolution has classically been centred on two opposing theories related to the original host for Leishmania as a digenetic parasite; i.e., was the first host a vertebrate or an invertebrate? Such information will certainly help us to better understand the origin and factors that play an important role in Leishmania dispersion and therefore in the epidemiology of leishmaniasis. The Phlebotominae ancestor emerged in the Triassic period, before the appearance of Leishmania (Jurassic) and placental mammals (Palaeocene). This hypothesis is further supported by an SSU rRNA data analysis indicating that Leishmania diverged from a trypanosomatid line of monogenetic insect parasites [140]. The oldest fossil ancestors of the modern sandflies date from the Cretaceous period (120 MYA, Lebanon), followed by Burmese fossil amber (Cretaceous, $100 \mathrm{MYA}$ ). A gap of approximately $80 \mathrm{MYA}$ is present from this Burmese fossil amber specimen until the next fossil found in Baltic amber (20 MYA), meaning that there is a serious gap in knowledge. According to the Burmese fossil amber specimen, ingested and free-living flagellates of $P$. proterus were found in habitats containing P. burmitis sandflies. In the Jurassic period, the reptiles were the predominant vertebrate fauna for many years. Despite their presence, there is no strong evidence, such as fossils, linking the sandfly lineage with ancient cold-blooded vertebrates. This absence or rarity of Leishmania in older reptiles suggests that sandflies with haematophagous habits were likely to be the first host of Leishmania. In addition, the greater range restriction of the sandfly vectors than the animal hosts of Leishmania parasites supports the much closer coevolutionary relationship of Leishmania and sandflies. Considering the above observations, it appears that monogenetic parasites of sandflies adapted to mammals some 90 MYA, giving rise to Leishmania. This adaptation likely took place during a period when mammals were diversifying into different orders during the separation of Africa and South America. Kerr [144] proposed a Palaearctic origin of Leishmania, suggesting that reptiles were the first vertebrate hosts of Leishmania, whereas Noyes [149] considered rodents to be the first vertebrate host. With the exception of the Sauroleishmania group, no human pathogenic Leishmania have been reported from reptiles. One the other hand, regarding some characteristics of sandflies, such as their restricted flight distance, short life cycle, slow larval development, and greater blood feeding preference for warm-blooded animals compared with cold-blooded species, it is assumed that these insects were the first host of Leishmania, but they have not played a major role in the Leishmania dispersion, particularly in regions that are unsuitable for sandfly survival. Hence, it is assumed that Leishmania were transferred by infected sandflies to local vertebrates, in which the parasite can survive for long period, after which the vertebrates, particularly the murid rodents, were the responsible for disease dispersion in the Old and New World. Muroids are a large superfamily of rodents. They have diversified into a large superfamily comprising over 1,500 species, including hamsters, gerbils, true mice, and rats as well as many other relatives. They now make up nearly one-third of all mammalian species, and they occupy a vast variety of habitats on every continent except for Antarctica. Comparison of the origin and distribution pattern of rodents proposed by Schenk et al. [170] (Steppan [171]) with the hypotheses of Leishmania appearance and dispersion suggests a close similarity in the distribution patterns of these groups, supporting the theory that they might be responsible for Leishmania dispersion in both the Old and New World.

\section{Concluding Remarks}

The evolutionary relationship between sandflies and Leishmania has implications for leishmaniasis interventions and control. It is therefore necessary to obtain information on the origin of Leishmania and the Phlebotominae sandflies and their chronological history of coevolution. Understanding these evolutionary relationships between different Leishmania and sandfly species is of epidemiological importance for the future prediction of Leishmania transmission patterns. 


\section{Key Learning Points}

- Understanding the current hypotheses of the origin and dispersion of Leishmania and sandflies, based on the available fossil evidence and molecular studies and the factors that play important role in these dispersions

- To have a knowledge about three-century history of sandflies and Leishmania classification as well as a complete description of Leishmania and sandfly fossils, with biological emergence date of each Leishmania and sandfly groups during different geographical periods from 550 million years ago until now

- An update of information on the current distribution and dispersion of different species of Leishmania (53 species), sandfly vectors (More than 800 species), and animal reservoirs in each geographical regions of Palearctic, Nearctic, Neotropic, Afrotropical, Oriental, Madagascar, and Australia

- A critical discussion on the different approaches that were used for Leishmana and sandfly classification, their advantages and disadvantages, their synonymy, and proposal of an updated classification for each species of Leishmania and sandfly

- Suggesting a complete list of the potential and proven sandfly vectors for each Leishmania species in the Old and New World

\section{Top Five Papers}

1. Lainson, R., Shaw, J. J. (1987) Evolution, classification and geographical distribution. In: W Peters, R Killick-Kendrick, editors. The Leishmaniases in Biology and Medicine, Academic Press, London, p. 1-120.

2. Cupolillo, E., Medina-Acosta, E., Noyes, H., Momen, H., Grimaldi, G. Jr. (2000) A revised classification for Leishmania and Endotrypanum. Parasitology Today, 16, $142-144$.

3. Kerr, S. F. (2000) Palaearctic Origin of Leishmania. Memorias de Instituto Oswaldo Cruz, 95, 75-80.

4. Poinar, Jr. G. O. (2004) Palaeomyia burmitis (Diptera: Phlebotomidae), a new genus and species of Cretaceous sandflies with evidence of blood-sucking habits. Proceedings of the Entomological Society of Washington, 106, 598-605.

5. Lewis, D. J. (1982) A taxonomic review of the genus Phlebotomus (Diptera: Psychodidae). Bulletin of the British Museum (Natural History), 45, 121-209. http://www. sandflycatalog.org/pdfs/116803.pdf

\section{Acknowledgments}

The authors are grateful for Prof. Petr Volf for his critical comments, which improved this manuscript. We also thank Prof. Paul Bates and two anonymous reviewers for their comments that improved greatly the manuscript.

\section{References}

1. Moreno J, Alvar J. Canine leishmaniasis: epidemiological risk and the experimental model. Trends Parasitol. 2002; 18: 399-405. PMID: 12377257 
2. Alvar J, Vélez ID, Bern C, Herrero M, Desjeux P, Cano J, et al. Leishmaniasis Worldwide and Global Estimates of Its Incidence. PLoS ONE. (2012); 7(5): e35671. doi: 10.1371/journal.pone.0035671 PMID: 22693548

3. Galati EAB. Classificacao de Phlebotominae. In: Rangel ER, Lainson R, editors. Flebotomineos do Brasil. Editora Fiocruz, Rio de Janeiro, Brazil. 2003; p. 23-52. 367pp.

4. Seccombe AK, Ready PD, Huddleston LM. A catalogue of Old World Phlebotomine sandflies (Diptera: Psychodidae). Occas Pap Syst Entomol. 1993; 8: 1-57.

5. Lewis DJ. A taxonomic review of the genus Phlebotomus (Diptera: Psychodidae). Bull Br Mus nat. 1982; 45: 121-209.

6. Theodor O. Psychodidae, Phlebotominae, p. 1-55. In E Lindner, Die Fliegen der Palaearktischen Region, 1958; Vol. 9, Psychodidae, E. Schweizerbart'scheVerlag, Stuttgart.

7. Williams P. Relationships of phlebotomine sandflies (Diptera). Mem Inst Oswaldo Cruz. 1993; 88: 177-183. PMID: 8107579

8. Young DG, Duncan MA. Guide to the Identification and Geographic Distribution of Lutzomyia Sandflies in Mexico, the West Indies, Central and South America (Diptera: Psychodidae). Mem Amer Inst Entomol 54, Associate Publishers, Gainesville, 1994; 881 pp.

9. Hennig W. Insektenfossilien aus der unteren Kreide. IV. Psychodidae (Phlebotominae), mit einer kritischen Übersicht über das phylogenetische System der familie und die bisher beschriebenen Fossilien (Diptera). Stutt Beit Natur (B). 1972; 241: 1-69.

10. Rispal R, Leger N. Numerical taxonomy of Old World Phlebotominae (Diptera: Psychodidae). I. Considerations of Morphological Characters in the genus Phlebotomus Rondani \& Berte. Mem Inst Oswaldo Cruz. 1998; 93: 793-785.

11. Aransay AM, Scoulica E, Tselentis Y, Ready PD. Phylogenetic relationships of Phlebotomine sandflies inferred from small subunit nuclear ribosomal DNA. Insect Mol Biol. 2000; 9: 157-168. PMID: 10762423

12. Perfil'ev PP. Phlebotomidae. Translation of Perfil'ev, 1966 Diptera: Family Phlebotomidae. Fauna SSSR. 1968; 93: 1-382.

13. Theodor O. Classification of the Old World species of the subfamily Phlebotominae (Diptera, Psychodidae). Bull Entomol Res.1948; 39: 85-115. PMID: 18865548

14. Lewis DJ, Young DG, Fairchild GB, Minter DM. Proposal for a stable classification of the phlebotomine sandflies (Diptera: Psychodidae). Sys Entomol. 1977; 2: 319-332.

15. Leng YJ. A preliminary survey of phlebotomine sandflies in limestone caves of Sichuan and Guizhou Provinces, South-West China, and description and discussion of a primitive new genus Chinius. Ann Trop Med Parasitol. 1987; 81: 311-317. PMID: 3662673

16. Galati E.A.B. Classificação, morfologia, terminologia e identificação de Adultos: Bioecologia e Identificação de Phlebotominae. In: Rangel E.F., Lainson R., editors. Flebotomíneos do Brasil. FIOCRUZ, Río de Janeiro, 2014. p. 367.

17. Lane RP. Sandflies (Phlebotominae). 1993; p. 78-113. In: Lane RP, Crosskey RW, editors. Medical Insects and Arachnids, Chapman \& Hall, London, 723 pp.

18. Lewis DJ. Functional morphology of the mouth parts in World phlebotomine sandflies. Proc R Soc London. 1975; 126: 497-532.

19. Lainson R, Shaw JJ. Evolution, classification and geographical distribution. In: Peters W, Killick-Kendrick R editors. The Leishmaniases in Biology and Medicine, Academic Press, London, 1987; p. 1120.

20. Sadlova J, Dvorak V, Seblova V, Warburg A, Votypka J, Volf P. Sergentomyia schwetzi is not a competent vector for Leishmania donovani and other Leishmania species pathogenic to humans. Parasites Vectors. 2013; 6: 186-196. doi: 10.1186/1756-3305-6-186 PMID: 23786805

21. Javadian E, Mesghali A. Checklist of phlebotominae sandflies (Diptera; Psychodidae) of Iran. Diptera, sandflies, Phlebotomus sp. checklist, Iran. Bull Soc Pathol Exot Filiales. 1975; 68, 207-9. PMID: 1242698

22. Theodor O, Mesghali A. On the Phlebotominae of Iran. J Med Entomol. 1964; 1: 285-300. PMID: 14222870

23. Lewis DJ. The Phlebotomine sandflies of West Pakistan (Diptera: Psychodidae). Bull. Br.Mus.nat (Natural History). 1967; 19: 1-57.

24. Rioux JA, Golvan YJ. Epidémiologie des leishmanioses dans le sud de la France. Monographie de I'INSERM (Paris). 1969; 37: 1-223.

25. Houin R, Abonnenc E, Denial M. Phlebotomes du sud de la Turquie. Resultats d'un sondage. Annales de parasitologie humaine et comparée. 1971; 46: 633-652. 
26. Bailly-Chaumara $\mathrm{H}, \mathrm{Abonnec} \mathrm{E}$, Pastre J. Contribution à l'étude des phlébotomes du Maroc (Diptera: Psychodidae). Données faunistiques et écologiques. Cahiers ORSTOM. Série Entomologie Médicale et Parazitologie. 1971; 4: 431-460.

27. Lewis DJ. The Phlebotomid sandflies of Yemen Arab Republic. Tropenmed Parasitol. 1974; 25 : $187-$ 197. PMID: 4425528

28. Gil Collado J. Phlebotomes et Leishmanioses en Espagne. In: Colloques Internationaux du C. N. R. S.: Ecologie des Leishmaniose. Ed. C. N. R. S. Paris, 1977; 177-190.

29. Croset H, Rioux JA, Maistre M, Bayar N. The phlebotomines of Tunisia (Diptera-Phlebotominae). A revision of the systematics, distribution and behaviour. Ann Parasitol Hum Comp. 1978; 53: 711-749. PMID: 754625

30. Artemiev MM. Sandflies (Diptera, Psychodidae. Phlebotominae) of Afghanistan, Ministry of Health: Malaria and Leishmania Institute Kabul, 1978; 87pp.

31. Lewis DJ, Buttiker W. Diptera: Fam. Psychodidae, subfam. Phlebotominae, pp. 252-285. In: Wittmer W, Buttiker W, editors. Fauna of Saudi Arabia. 1980; Vol. 2., 443 pp. Basle, Pro Entomologia/CibaGeigy.

32. Abul-Hab J, Ahmed SA. Revision of the family Phlebotomidae (Diptera) in Iraq. J Biol Sci Res. 1984; 7: 1-64.

33. Dedet JP, Addadi K, Belazzoug S. Les phlébotomes (Diptera, Psychodidae) d'Algérie. Cahier ORSTOM, série Entomologie Médicale et Parasitologie. 1984; 22: 99-127.

34. Lane RP. Recent advances in the systematics of Phlebotomine sandflies. Insect Sci Appl. 1986; 7: 225-230.

35. Léger N, Pesson B, Madulo-Leblond G. Les phlebotomes de Grece. Biol Gallo-hellenica. 1986; 11: 165-192.

36. Lane RP, Abdel-Hafez S, Kamhawi S. The distribution of Phlebotomine sandflies in the principal ecological of Jordan. Med Vet Entomol J. 1988; 2: 237-246.

37. Esseghir S, Ready PD, Ben-Ismail R. Speciation of Phlebotomus sandflies of the subgenus Larroussius coincided with the late Miocene-Pliocene aridification of the Mediterranean subregion. Biol J Linnean Soc. 2000; 70: 189-219.

38. Killick-Kendrick R, Killick-Kendrick M. Biology of sandfly vectors of Mediterranean canine leishmaniasis. In: Killick-Kendrick R, editor. Canine leishmaniasis: an update. Proc. Int. Can. Leishm. Forum, Barcelona, Spain, Intervet Int., Boxmeer, The Netherlands, 1999; pp 26-31.

39. Maroli M, Feliciangeli D, Bichaud L, Charrel R, Gradoni L. Phlebotomine sandflies and the spreading of leishmaniases and other diseases of public health concern. Medical Vet Entomol J. 2012; 27: 12347.

40. Zhang L, Ma Y, Xu J. Genetic differentiation between sandfly populations of Phlebotomus chinensis and Phlebotomus sichuanensis (Diptera: Psychodidae) in China inferred by microsatellites. Parasites Vectors. 2013; 6: 115. doi: 10.1186/1756-3305-6-115 PMID: 23607337

41. Galliard H, Nitzulescu V. Contribution à l'etude des phlebotomes du Gabon. Phlebotomus sanneri n. sp. Ann Parasitol Hum Comp. 1931; 9: 233-246.

42. Grepin G. A Check-List of Sandflies (Diptera-Phlebotominae) of Central African Republic. Ann Parasitol Hum Comp. 1983; 58: 85-90. PMID: 6870100

43. Ashford RW. Sandflies (Diptera: Phlebotomidae) from Ethiopia: taxonomi and biological notes. J Med Entomol. 1974; 11: 605-616. PMID: 4455925

44. Davidson IH. The subgenus Anaphlebotomus of Phlebotomus (Diptera: Psychodidae) in southern Africa. J Entomol Soc South Africa. 1981; 44: 259-264.

45. Léger N, Depaquit J, Robert V. les phlébotomes de madagascar (Diptera: Psychodidae). iv-description de Sergentomyia (rondanomyia) goodmani n. sp. rétablissement du sous-genre Rondanomyia theodor. Parasite. 2005; 12: 51-57. PMID: 15828582

46. Léger N, Depaquit J, Gay F. Description of the sandfly species Chinius samarensis n. sp. (Psychodidae; Diptera) from the Philippines. Pathog Glob Health. 2012; 106: 346-351. doi: 10.1179/ 2047773212Y.0000000041 PMID: 23182139

47. Léger N, Depaquit J, Gay F. Chinius eunicegalatiae n. sp. (Diptera; Psychodidae), a cavernicolous sandfly from Laos. Ann TropMed Parasitol. 2010; 104: 595-600.

48. Lewis DJ. The Phlebotomine sandflies (Diptera: Psychodidae) of the Oriental Region. Bull Br Mus (Natural History). 1978; 37: 217-343.

49. Lewis DJ, Dyce A. Taxonomy of the Australasian Phlebotominae (Diptera: Psychodidae) with revision of genus Sergentomyia from the region. Invertebrate Taxonomy. 1988; 2(6): 755-804. 
50. Schodde R, Calaby JH. The biogeography of the Australo-Papuan Bird and mammal faunas in relation to Torres Strait, p. 257-300. In: Bridge and barrier: the natural and cultural history of Torres Strait. Australian Nat. Univ., 1972; Canberra, Australia.

51. Quate LW, Quate SH. A monograph of Papuan Psychodidae, including Phlebotomus. Pac Insects. 1967; 15: 1-216.

52. Dyce AL, Wellings G. Phlebotomine sandflies (Diptera: Psychodidae) from caves in Australia. Parasitologia. 1991; 33: 193-8.

53. Lewis DJ, Dyce AL. The subgenus Australophlebotomus Theodor of Phlebotomus Rondani and Berté (Diptera: Psychodidae). J Aust Entomol Soc. 1982; 21: 37-54.

54. Galati EAB, Nunes VLB, Rego FA, Oshiro ET, Chang MR. Estudo de flebotomíneos (Diptera: Psychodidae) em foco de leishmaniose visceral no estado de Mato Grosso do Sul, Brasil. Cad Saúde Pública. 1997; 31: 378-390.

55. Martins AV, Williams P, Falcao AL. (1978) American Sandflies (Diptera: Psychodidae, Phleboiominae). Academia Brasiliera de Ciencias, Rio de Janeiro.

56. Young DG, Lawyer PG. New World vectors of the leishmaniases. In: Harris KF, Current Topics in Vector Research, Vol. 4. Springer-Verlag, New York, 1987; p. $29-37$.

57. Young DG, Perkins PV. Phlebotomine sandflies of North America (Diptera: Psychodidae). Mosq News. 1984; 44: 263-304.

58. Young DG. A review of the bloodsucking psychodid flies of Colombia (Diptern: Phlebotominae and Sycoracinae). Tech. Bull. 806, Agric. Exp. Station, IFAS, Univ. Florida, Gainesville. 1979; 226 p.

59. Young DG, Rogers TE. The Phlebotomine sandfly fauna of Ecuador. J Med Entomol. 1984; 24: 651665.

60. Murillo J, Zeledon R. Flebotomos de Costa Rica. Brenesia: Rev. Cienc. Nat. Museo Nac. Costa Rica, $1985 ; 137 \mathrm{p}$

61. Young DG, Murillo J. A new Phlebotomine sandfly, Lutzomyia zeledoni, n. sp. (Diptera: Psychodidae) from Central America. J Med Entomol. 1984; 21: 711-713.

62. Ryan L. Flebótomos do Estado do Pará, Brasil (Diptera: Psychodidae: Phlebotominae), Tech. Doc. No. 1, Instituto Evandro Chagas, Belém, 1986; 154 pp.

63. Lebbe J, Vignes R, Dedet JP. Computer Aided Identification of Phlebotomine Sandflies of French Guiana (Diptera: Psychodidae). Publication de I'Institut Pasteur de la Guyane française, Cayenne, 1987; $165 \mathrm{pp}$.

64. Feliciangeli MD, Rabinovich J. Abundance of Lutzomyia ovallesi but not Lu. gomezi (Diptera: Psychodidae) correlated with cutaneous leishmaniasis incidence in north-central Venezuela. M Vet Entomol J. 1998; 12: 121-131.

65. Forattini OP. Entomologia Médica. Psychodidae. Phlebotominae. Leismanioses. Bartonelose, 1973; Vol 4, Edgar Blücher Ltda., São Paulo.

66. Galati EAB, Fonseca MB, Marassá AM, Bueno EFM. Dispersal and survival of Nyssomyia intermedia and Nyssomyia neivai (Diptera: Psychodidae: Phlebotominae) in a cutaneous leishmaniasis endemic area of the speleological province of the Ribeira Valley, State of São Paulo, Brazil. Mem Inst Oswaldo Cruz. 2009; 104: 1148-1158. PMID: 20140376

67. Theodor O. On the classification of American Phlebotominae. J Med Entomol. 1965; 2: 171-197. PMID: 5827575

68. Andrade Filho JD, Brazil RP. Relationships of new word Phlebotomine sandflies (Diptera: Psychodidae) based on fossil evidence. Mem Inst Oswaldo Cruz. 2003; 98: 145-149.

69. Krzeminski W, Krzeminska E. Triassic Diptera: descriptions, revisions and phylogenetic relations. Acta Zool Cracov. 2003; 46: 153-184.

70. Blagoderov VA, Grimaldi DA, Fraser NC. How time flies for flies: diverse Diptera from the Triassic of Virginia and early radiation of the order. Am Mus Novit. 2007; 3572: 1-39.

71. Poinar G. Lutzomyia adiketis sp. n. (Diptera: Phlebotomidae), a vector of Paleoleishmania neotropicum sp. n. (Kinetoplastida: Trypanosomatidae) in Dominican amber. Parasites Vectors. 2008; 1, 22. doi: 10.1186/1756-3305-1-22 PMID: 18627624

72. Perrichot $\mathrm{V}$, Neraudeau D, Nel A, de Ploeg G. A reassessment of the Cretaceous amber deposits from France and their palaeontological significance. Afr Invertebr. 2007; 48: 213-227.

73. Ansorge J. Tanyderidae and Psychodidae (Insecta: Diptera) from the lower Jurassic of Northeastern Germany. Palaontologische Zeitschrift. 1994; 68: 199-210.

74. Declòs X, Arillo A, Penalver E, Barron E, Soriano C, Lopez del Valle R, et al. Fossiliferous amber deposits from Cretaceous (Albian) of Spain. Comptes Rendus de l'Academie des Sciences-Series IIA-Earth and Planetary Science (Comptes Rendus Palevol). 2007; 6: 135-149. 
75. Poinar G. O. Jr Palaeomyia burmitis (Diptera: Phlebotomidae), a new genus and species of Cretaceous sandflies with evidence of blood-sucking habits. Proc Entomol Soc Wash. 2004; 106: 598-605.

76. Azar D, Nel A, Solignac M, Paicheler JC, Bouchet F. New genera and species of phlebotomid and psychodid flies from the Lower Cretaceous amber of Lebanon (Insecta: Diptera: Phlebotomidae, Psychodidae). Palaeontol. 1999; 42: 1131-1136.

77. Stuckenberg BR. New fossil species of Phlebotomus and Haematopota in Baltic Amber (Diptera: Psychodidae, Tabinidae). Ann Natal Mus. 1975; 22: 455-464.

78. Kaddumi H.F.. 2005. Amber of Jordan. The oldest prehistoric insects in fossilised resins. Eternal River Museum of Natural History, Jordan: 168 pp.

79. Solorzano-Kraemer M. Systematic, palaeoecology, and palaeobiogeography of the insect fauna from the Mexican amber. Palaeontogr Abt. 2007; 282: 1-133.

80. Antoine PO, Franceschi D, Flynn JJ, Nel A, Baby P, Benammi M, et al. Amber from western Amazonia reveals Neotropical diversity during the middle Miocene. PNAS. 2006; 113: 13595-13600.

81. Killick-Kendrick R. Phlebotomine vectors of the leishmaniases: a review. Med Vet Entomol J. 1990; 4: $1-24$.

82. Tuon FF, Neto VA, Amato VS. Leishmania: origin, evolution and future since the Precambrian. FEMS Immunol Med Microbiol. 2008; 54: 158-66. doi: 10.1111/j.1574-695X.2008.00455.x PMID: 18631183

83. Noyes HA, Morrison DA, Chance ML, Ellis JT. Evidence for a Neotropical Origin of Leishmania. Mem Inst Oswaldo Cruz. 2000; 95: 575. PMID: 10904417

84. Flegontov P, Votýpka J, Skalick'y T, Logacheva MD, Penin AA, Tanifuji G, et al. Paratrypanosoma is a novel early-branching trypanosomatid. Curr Biol. 2013; 23: 1787-93. doi: 10.1016/j.cub.2013.07. 045 PMID: 24012313

85. Maslov DA, Votýpka J, Yurchenko V, Lukeš J. Diversity and phylogeny of insect trypanosomatids: all that is hidden shall be revealed. Trends Parasitol. 2013; 1: 43-52.

86. Teixeira MM, Borghesan TC, Ferreira RC, Santos MA, Takata CS, Campaner M, et al. Phylogenetic validation of the genera Angomonas and Strigomonas of trypanosomatids harboring bacterial endosymbionts with the description of new species of trypanosomatids and of proteobacterial symbionts. Protist. 2011; 162: 503-524. doi: 10.1016/j.protis.2011.01.001 PMID: 21420905

87. Votýpka J, Suková E, Kraeva N, Ishemgulova A, Duží I, Lukeš J, et al. Diversity of Trypanosomatids (Kinetoplastea: Trypanosomatidae) Parasitizing Fleas (Insecta: Siphonaptera) and Description of a New Genus Blechomonas gen. n. Protist. 2013; 164: 763-781. doi: 10.1016/j.protis.2013.08.002 PMID: 24113136

88. Hamilton PT, Votýpka J, Dostálová A, Yurchenko V, Bird NH, Lukeš J, et al. Infection Dynamics and Immune Response in a Newly Described Drosophila-Trypanosomatid Association. MBio. 2015; 6: pii: e01356-15. doi: 10.1128/mBio.01356-15 PMID: 26374124

89. Dantas-Torres F, Lorusso V, Testini G, de Paiva-Cavalcanti M, Figueredo L A, Stanneck D, et al Detection of Leishmania infantum in Rhipicephalus sanguineus ticks from Brazil and Italy. Parasitol Res. 2010; 106: 857-60. doi: 10.1007/s00436-010-1722-4 PMID: 20127362

90. Slama D, Haouas N, Remadi L, Mezhoub H, Babba H, Chaker E. First detection of Leishmania infantum (Kinetoplastida: Trypanosomotidae) in Culicoides spp. (Diptera: Ceratopogonidae). Parasits Vectors. 2014; 7: 51.

91. Solano-Gallego L, Rossi L, Scroccaro AM, Montarsi F, Caldin M, Furlanello T, et al. Detection of Leishmania infantum DNA mainly in Rhipicephalus sanguineus male ticks removed from dogs living in endemic areas of canine leishmaniosis. Parasites Vectors. 2012; 5: 98. doi: 10.1186/1756-3305-5-98 PMID: 22613502

92. Buck G, Courdurier J, Dorel R, Quesnel JJ. The first case of canine leishmaniasis in Madagascar. Bull Soc Pathol Exot. 1951; 44: 428-30.

93. Killick-Kendrick R, Killick-Kendrick M, Tang Y, Bastien P. Metacyclic promastigotes of Leishmania in the salivary glands of experimentally infected phlebotomine sandflies. Parasite. 1996; 3: 55-60.

94. Lainson R. The Neotropical Leishmania species: a brief historical review of their discovery, ecology and taxonomy. Revista Pan-Amazônica de Saúde. 2010; 1: 13-32.

95. Adler S. Leishmania. Adv Parasitol. 1964; 2: 35-96. PMID: 14321783

96. Belova EM. Reptiles and their importance in epidemiology of leishmaniasis. Bull World Health Organ. 1971; 44: 553-560. PMID: 5316256

97. Lainson R, Shaw JJ. Leishmanias and leishmaniasis of the New World, with particular reference to Brazil. Bull Pan Am Health Organ.1973; 7: 1.

98. Lainson R, Shaw JJ. Leishmaniasis of the New World: Taxonomic problems. British med Bull. 1972; 28: 44 . 
99. Bray RS, Ashford RW, Bray MA. The parasite causing cutaneous leishmaniasis in Ethiopia. Trans R Soc Trop Med Hyg. 1973; 67: 345-8. PMID: 4778189

100. Vickerman K. (1976) The diversity of the kinetoplastid flagellates. In: Lumsden WHR, Evans DA, editors. Biology of the kinetoplastida. London: Academic Press. p. 1-34.

101. Lainson R, Ready PD, Shaw JJ. Leishmania in phlebotomid sandflies. VII. On the taxonomic status of Leishmania peruviana, causative agent of Peruvian "uta", as indicated by its development in the sandfly, Lutzomyia longipalpis. Proc R Soc London. 1979; 206: 307-318.

102. Saf'janova VM. Classification of the genus Leishmania Ross. Chapter 11 (in Russian). In: The Leishmaniasis. Protozoology, Academy of Sciences, USSR All Union Society of Protozoologists, Lennigrad, Part 7, 1982; p. 95-101.

103. Ranque $P$. Etude morphologique et biologique de quelques Trypanosomides recoltes au senegal. These sciences Marseille, 1973; 378, pp.

104. Killick-Kendrick R, Lainson R, Rioux JA, Saf'janova VM. The taxonomy of Leishmania-like parasites of reptiles. In: Rioux JA. Leishmania: Taxonomie et Phylogenèse. Application Éco-epidemiologiques (Colloque International du CNRS/INSERM, 1984), 1986; IMEE, Montpellier.

105. Moreno G, Rioux JA, Lanotte G, Pratlong F, Serres E. Le complexe Leishmania donovani s.I. Analyse enzymatique et traitement nume'rique. Individualisation du complexe Leishmania infantum. In: Rioux JA, editor. Leishmania: Taxonomie et Phylogenese. Application Éco-epidemiologiques (Colloque International du CNRS/INSERM, 1984), 1986; IMEE, Montpellier. pp. 105-117.

106. Thomaz-Soccol V, Lanotte G, Rioux JA, Pratlong F, Martini-Dumas A, Serres E. Monophyletic origin of the genus Leishmania Ross, 1903. Ann Parasitol Hum Comp. 1993; 68: 107-108. PMID: 8215109

107. Cupolillo E, Grimaldi G Jr, Momen H. A general classification of New World Leishmania using numerical zymotaxonomy. Am J Trop Med Hyg. 1994; 50: 250-311.

108. Lanotte G, Rioux JA, Maazoun R, Pasteur N, Pratlong F, Lepart J. The application of a numerical method to the taxonomy of the genus Leishmania Ross, 1903. The recognition of 146 original lines in the Old World. Use of allozymic characters. Epidemiological and phyletic significance. Ann Parasitol Hum Comp. 1981; 56: 575-91. PMID: 7337375

109. Le Blanq SM, Belehu A, Peters W. Leishmania in the Old world: 3 the distribution of L. aethiopica zymodemes. Trans R Soc Trop Med Hyg. 1986; 80: 360-366. PMID: 3798530

110. Rioux JA. Taxonomy of Leishmania. Use of isoenzymes. Suggestions for a new classification. Ann Parasitol Hum Comp. 1990; 65: 11-125.

111. Hennig W. Phylogenetic systematics. Ann Rev Entomol. 1965; 10: 97-116.

112. Rioux JA, Lanotte G. Apport de la cladistique à l'analyse du genre Leishmania Ross 1903 (Kinetoplastida: Trypanosomatidae). Corollaires epidemiologiques. Biosyst. 1993; 8: 79-80.

113. Dedet JP. Current status of epidemiology of leishmaniases. In: Farrell JP editor. Leishmania series: World class parasites, Vol. 4. London: Kluwer academic press. 2002. p. 1-10.

114. Cupolillo E, Medina-Acosta E, Noyes H, Momen H, Grimaldi G Jr. A revised classification for Leishmania and Endotrypanum. Parasitol Today. 2000; 16: 142-144. PMID: 10725899

115. Pothirat $T$, Tantiworawit $A$, Chaiwarith $R$, Jariyapan $N$, Wannasan $A$, et al. First Isolation of Leishmania from Northern Thailand: Case Report, Identification as Leishmania martiniquensis and Phylogenetic Position within the Leishmania enriettii Complex. PLoS Negl Trop Dis. 2014; 8: e3339. doi: 10.1371/ journal.pntd.0003339 PMID: 25474647

116. Kwakye-Nuako G, Mosore MT, Duplessis C, Bates MD, Puplampu N, Mensah-Attipoe I, Desewu K, Afegbe G, Asmah RH, Jamjoom MB, Ayeh-Kumi PF, Boakye DA, Bates PA. First isolation of a new species of Leishmania responsible for human cutaneous leishmaniasis in Ghana and classification in the Leishmania enriettii complex. Int J Par. 2015; 45: 679-684.

117. Asato $\mathrm{Y}$, Oshiro M, Myint CK, Yamamoto $\mathrm{Y}$, Kato H, Marco JD, et al. Phylogenic analysis of the genus Leishmania by cytochrome b gene sequencing. Exp Parasitol. 2009; 121: 352-361. doi: 10.1016/j. exppara.2008.12.013 PMID: 19159626

118. Schönian G, El Fari M, Lewin S, Schweynoch C, Presber W. Molecular epidemiology and population genetics in Leishmania. Med Microb Immunol. 2001; 190: 61-63.

119. Schwenkenbecher JM, Wirth T, Schnur LF, Jaffe CL, Schallig H, Al-Jawabreh A, et al. Microsatellite analysis reveals genetic structure of Leishmania tropica. Int J Parasitol. 2006; 36: 237-246. PMID: 16307745

120. Jamjoom MB, Ashford RW, Bates PA, Chance ML, Kemp SJ, Watts PC, et al. Leishmania donovani is the only cause of visceral leishmaniasis in East Africa; previous descriptions of $L$. infantum and " $L$. archibaldi" from this region are a consequence of convergent evolution in the isoenzyme data. Parasitol. 2004; 129: 399-409. 
121. Kuhls K, Keilonat L, Ochsenreither S, Schaar M, Schweynoch C, Presber W, et al. Multilocus microsatellite typing (MLMT) reveals genetically isolated populations between and within the main endemic regions of visceral leishmaniasis. Microbes Infect. 2007; 9: 334-343. PMID: 17307010

122. Kuhls K, Mauricio IL, Pratlong F, Presber W, Schonian G. Analysis of ribosomal DNA internal transcribed spacer sequences of the Leishmania donovani complex. Microbes Infect. 2005; 7: 12241234. PMID: 16002315

123. Kuhls K, Alam MZ, Cupolillo E, Ferreira GEMF, Mauricio IL, Oddone R, et al. Comparative microsatellite typing of New World Leishmania infantum reveals low heterogeneity among populations and its recent Old World origin. PLoS Negl Trop Dis.2011; 5: e1155. doi: 10.1371/journal.pntd.0001155 PMID: 21666787

124. Leblois R, Kuhls K, François O, Schönian G, Wirth T. Guns, germs and dogs: on the origin of Leishmania chagasi. Infect Genet Evol. 2011; 11: 1091-1095. doi: 10.1016/j.meegid.2011.04.004 PMID: 21511057

125. Fraga J, Montalvo AM, De Doncker S, Dujardin JC, Van der Auwera G. Phylogeny of Leishmania species based on the heat-shock protein 70 gene. Infect Genet Evol. 2010; 10: 238-245. doi: 10.1016/j. meegid.2009.11.007 PMID: 19913110

126. Schönian G, Mauricio I, Cupolillo E. Is it time to revise the nomenclature of Leishmania? Trends Parasitol. 2010; 26: 466-9. doi: 10.1016/j.pt.2010.06.013 PMID: 20609626

127. Schönian G, Cupolillo E, Mauricio I. Molecular evolution and phylogeny of Leishmania. In: PonteSucre A, Diaz E, Padrón-Nieves M, editors. Drug Resistance in Leishmania Parasites: Consequences, Molecular Mechanisms and Possible Treatments. Springer Wien Heidelberg New York, Dordrecht London; 2013. p.15-44.

128. Telford SR Jr. The kinetoplastid hemoflagellates of reptiles, p. 161-223. In: Kreier JP, Baker JR, editors. Parasitic Protozoa, 2nd ed., 1995; Vol. 10, Academic Press, San Diego.

129. Saf'janova WM. The problems of classification and phylogeny of the Leishmania. In: Rioux JA., editor. Leishmania: Taxonomie et Phylogenese. Applications Eco-epidemiologiques 1986; pp. 247-255. Montpellier: 1MEEE.

130. Lukeš J, Skalický T, Týč J, Votýpka J, Yurchenko V. Evolution of parasitism in kinetoplastid flagellates. Mol Biochem Parasitol. 2014; 195: 115-122. doi: 10.1016/j.molbiopara.2014.05.007 PMID: 24893339

131. Franco AMR, Machado GMC, Moreira CFS, Grimaldi G. Minicircle kDNA Microheterogeneity in Endotrypanum Indicate Diversity within this Genus. Mem Inst Oswaldo Cruz. 2000; 95: 189-191.

132. Dooijes D, Chaves I, Kieft R, Dirks-Mulder A, Martin W, Borst P. Base J originally found in kinetoplastida is also a minor constituent of nuclear DNA of Euglena gracilis. Nucleic Acids Res. 2000; 28: 3017-3021. PMID: 10931915

133. Roger A, Hug L. The origin and diversification of eukaryotes: problems with molecular phylogenetics and molecular clock estimation. Phil Trans R Soc A. 2006; 361: 1039-1054.

134. Poinar GO Jr, Poinar R. Fossil evidence of insect pathogens. J Invertebr Pathol. 2004; 89: 243-250.

135. Cavalier-Smith T. Rooting the tree of life by transition analyses. Biol Direct. 2006; 1: 19. PMID: 16834776

136. Kerr SF. Molecular trees of trypanosomes incongruent with fossil records of hosts. Mem Inst Oswaldo Cruz. 2006; 101: 25-30.

137. Azar D, Nel A. Fossil Psychodoid flies and their relation to parasitic diseases. Mem Inst Oswaldo Cruz. 2003; 97: 35-37.

138. Gullan PJ, Cranston PS. The Insects: An Outline of Entomology, 2nd Edition. Wiley-Blackwell, London, 2000; 470 pp.

139. Momen H, Cupolillo E. Speculations on the Origin and Evolution of the Genus Leishmania. Mem Inst Oswaldo Cruz. 2000; 95: 583. PMID: 10904419

140. Fernandes AP, Nelson K, Beverley SM. Evolution of nuclear ribosomal RNAs in kinetoplastid protozoa-perspectives on the age and origins of parasitism. PNAS. 1993; 90: 11608-11612. PMID: 8265597

141. Vrba ES. Mammals as a key to evolutionary theory. J Mammal. 1992; 73: 1-28.

142. Lysenko AJ. Distribution of leishmaniasis in the Old World. Bull World Health Organization. 1971; 44, 515-520.

143. Nowak RM. Walker's Mammals of the World, 5th ed., Vol. II. The Johns Hopkins University Press, Baltimore and London, 1991; p. 643-1629.

144. Kerr SF. Palaearctic Origin of Leishmania. Mem Inst Oswaldo Cruz. 2000; 95: 75. PMID: 10656708 
145. Kerr SF, Merkelz R, MacKinnon C. Further support for a palaearctic origin of Leishmania. Mem Inst Oswaldo Cruz. 2000; 95: 579-581. PMID: 10904418

146. Lukeš J, Mauricio IL, Schönian G, Dujardin JC, Soteriadou K, Dedet JP, et al. Evolutionary and geographical history of the Leishmania donovani complex with a revision of current taxonomy. PNAS. 2007; 104: 9375-9380. PMID: 17517634

147. Killick-Kendrick R. Some epidemiological consequences of the evolutionary fit between Leishmaniae and their phlebotomine vectors. Bull Soc Pathol Exot. 1985; 78: 747-755.

148. Mauricio IL, Stothard JR, Miles MA. The strange case of Leishmania chagasi. Parasitol Today. 2000; 16: 188-189. PMID: 10782075

149. Noyes H. Implications of a Neotropical origin of the genus Leishmania. Mem Inst Oswaldo Cruz. 1998; 93: 657-661. PMID: 9830534

150. Croan DG, Morrison DA, Ellis JT. Evolution of the genus Leishmania revealed by comparison of DNA and RNA polymerase gene sequences. Mol Biochem Parasitol. 1997; 89: 149-159. PMID: 9364962

151. Wirth DF, McMahon-Pratt D. Rapid identification of Leishmania species by specific hybridization of kinetoplast DNA in cutaneous lesions. PNAS. 1982; 79: 6999-7003. PMID: 6960359

152. Sang DK, Njeru WK, Ashford RW. A zoonotic focus of cutaneous leishmaniasis due to Leishmania tropica at Utut, Fift Valley Province, Kenya. Trans Roy Soci Trop Med Hyg. 1994; 88: 35-37.

153. Ready PD, Pesson B. Hybridization, introgression and distribution of vectorial traits. International Symposium on Phlebotomine Sandflies III, 1999; Montpellier, France.

154. Kamhawi S, Ramalho-Ortigao M, Pham VM, Kumar S, Lawyer PG, Turco SJ, Barillas-Mury C, Sacks DL, Valenzuela JG. A role for insect galectins in parasite survival. Cell. 2004; 119: 329-41. PMID: 15543683

155. Dostálová A, Volf P. Leishmania development in sandflies: parasite-vector interactions overview. Parasite Vector. 2012; 5: 276-288.

156. Volf P, Benkova I, Myskova J, Sadlova J, Campino L, Ravel C. Increased transmission potential of Leishmania major/Leishmania infantum hybrids. Int J Parasitol. 2007; 37: 589-93. PMID: 17376453

157. Akhoundi M, Parvizi P, Baghaei A, Depaquit J. The subgenus Adlerius Nitzulescu (Diptera, Psychodidae, Phlebotomus) in Iran. Acta Trop. 2011; 122: 7-15. doi: 10.1016/j.actatropica.2011.10.012 PMID: 22079375

158. Strazzulla A, Cocuzza S, Pinzone MR, Postorino MC, Cosentino S, Serra A, et al. Mucosal Leishmaniasis: An Underestimated Presentation of a Neglected Disease. Bio Med Res Int. 2013; 10: 1-8.

159. Alborzi A, Rasouli M, Shamsizadeh A. Leishmania tropica-isolated patient with visceral leishmaniasis in southern Iran. Am J Trop Med Hyg. 2006; 74: 306-307. PMID: 16474088

160. Gállego M, Pratlong F, Fisa R, Riera C, Rioux JA, Dedet JP, et al. The life-cycle of Leishmania infantum MON-77 in the Priorat (Catalonia, Spain) involves humans, dogs and sandflies; also literature review of distribution and hosts of $L$. infantum zymodemes in the old world. Trans $R$ Soc Trop Med Hyg. 2001; 95: 269-271. PMID: 11490994

161. Ready PD. Epidemiology of visceral leishmaniasis. Clinic Epidemiol. 2014; 6: 147-154.

162. Ready PD, Fraiha H, Lainson R, Shaw J. Psychodopygus as a genus: reasons for a flexible classification of the Phlebotomine sandflies (Diptera: Psychodidae). J Med Entomol. 1980; 17: 75-88.

163. Quate LW, Fairchild GB. Phlebotomus sandflies of Malaya and Borneo. Pac Insects. 1961; 3: 203222.

164. Abonnenc E. Les phlebotomes de la region ethiopienne (Diptera: Psychodidae). Mémoire de l'ORSTOM. 1972; No.55.

165. Abonnenc E, Minter DM. Bilingual Keys for the identification of the sandflies of the Ethiopian region. Cahier ORSTOM, série Entomologie Médicale et Parasitologie. 1965; 5: 24-63.

166. Artemiev MM, Neronov V. Distribution and ecology of sandflies of the world (genus Phlebotomus). Institute of Evolution, Morphology and Animal Ecology, Moscow, 1984; pp 1-208.

167. Van der Linde K, Houle D, Spicer GS, Steppan SJ. A supermatrix-based molecular phylogeny of the family Drosophilidae. Gen Res. 2010; 92: 25-38.

168. Perrotey S, Mahamdallie SS, Pesson B, Richardson KJ, Gallego M, Ready PD. Postglacial dispersal of Phlebotomus perniciosus into France. Parasite. 2005; 12: 283-291. PMID: 16402559

169. Philippe H. Molecular phylogeny of kinetoplastids. In: Coombs GH, Vickerman K, Sleigh MA, Warren A, editors. Evolutionary Relationships among Protozoa. Kluwer Academic Publishers, Dordrecht/ Boston/London. 1998; p. 195-212. 
170. Schenk JJ, Rowe KC, Steppan SJ. Ecological Opportunity and Incumbency in the Diversification of Repeated Continental Colonizations by Muroid Rodents. Syst biol. 2013; 62: 837-864. doi: 10.1093/ sysbio/syt050 PMID: 23925508

171. Steppan, S. Passways of continental Muroid immigration, Map: Scott Steppan, Florida State University, Source: Florida State University (personal document), 2013; http://museumvictoria.com.au/ about/media-centre/news/january-2014/story3/.

172. Peters W, Pasvol G. Atlas of Tropical Medicine and Parasitology, sixième Edition. 2007. Elsevier Mosby.

173. Añez N, Nieves E, Scorza JV. The taxonomic status of Leishmania garnhami, indicated by its pattern of development in the vector. Mem Inst Oswaldo Cruz. 1985; 80: 113-119. PMID: 4088042

174. Marsella R, Ruiz de Gopegui R. Leishmaniasis: a re-emerging zoonosis. Int J Dermatol. 1998; 37: 801-814. PMID: 9865863

175. Hamarsheh O. Distribution of Leishmania major zymodemes in relation to populations of Phlebotomus papatasi sandflies. Parasites Vectors. 2011; 4: 9. doi: 10.1186/1756-3305-4-9 PMID: 21266079

176. Saenz RE, Paz HM, Johnson CM, Marr JJ, Nelson DJ, Pattishall KH, et al. Treatment of American cutaneous leishmaniasis with orally administered allopurinol riboside. J Infect Dis. 1989; 160: 153158. PMID: 2659681

177. Guerbouj S, Guizani I, De Doncker S, Dujardin JC, Nuwayri-Salti N. Identification of Lebanese dermotropic putative Leishmania archibaldi isolates by gp63 PCR-RFLP. Trans R Soc Trop Med Hyg. 2001; 95: 687-688. PMID: 11816446

178. Ardehali S, Moattari A, Hatam GR, Hosseini SM, Sharifi I. Characterization of Leishmania isolated in Iran: Serotyping with species specific monoclonal antibodies. Acta Trop. 2000; 75: 301-307. PMID: 10838213

179. Falqueto A, Cupolillo E, Machado GM, de Carvalho-Paes LE, Grimaldi G Júnior. A new enzymatic variant of Leishmania (Leishmania) forattinii isolated from Proechimys iheringi (Rodentia, Echimydae) in Espírito Santo, Brazil. Mem Inst Oswaldo Cruz. 1998; 93: 795-798. PMID: 9921304

180. De Pita-Pereira D, Cardoso MAB, Alves CR, Brazil RP, Britto C. Detection of natural infection in Lutzomyia cruzi and Lutzomyia forattinii (Diptera: Psychodidae: Phlebotominae) by Leishmania infantum chagasi in an endemic area of visceral leishmaniasis in Brazil using a PCR multiplex assay. Acta Trop. 2008; 107: 66-69. doi: 10.1016/j.actatropica.2008.04.015 PMID: 18502392

181. Lainson R, Ward RD, Shaw JJ. Experimental transmission of Leishmania chagasi, causative agent of neotropical visceral leishmaniasis, by the sandfly Lutzomyia longipalpis. Nature. 1977; 266: 628630. PMID: 859627

182. Rassi Y, Abai MR, Oshaghi MA, Javadian E, Sanei A, Rafidzadeh S, Arzamani K. First detection of Leishmania infantum in Phlebotomus kandelakii using molecular methods in north-eastern Islamic Republic of Iran. East Mediterr Health J. 2012; 18: 387-392. PMID: 22768703

183. Akhoundi M, Baghaei A, Depaquit J, Parvizi P. Molecular Characterization of Leishmania Infection from Naturally Infected Sandflies Caught in a Focus of Cutaneous Leishmaniasis (Eastern Iran). J Arthropod Borne Dis. 2013; 7: 122-131. PMID: 24409437

184. Kassiri H, Javadian E, Sharififard M. Monthly activity of Phlebotominae sandflies in Sistan-Baluchistan Province, Southeast Iran. J Insect Sci. 2013; 13: 153. doi: 10.1673/031.013.15301 PMID: 24784790

185. Fairchild GB, Theodor O. On Lutzomyia flaviscutellata (Mangabeira) and L. Olmeca (Vargas and Diaz-Najera) (Diptera: Psychodidae). J Med Entomol. 1971; 8: 153-159. PMID: 5157836

186. Feliciangeli MD, Rodriguez N, Bravo A, Arias F, Guzman B. Vectors of cutaneous leishmaniasis in north-central Venezuela. Med Vet Entomol J. 1994; 8: 317-324.

187. Gómez EA, Hashiguchi Y. Monthly variation in natural infection of the sandfly Lutzomyia ayacuchensis with Leishmania mexicana in an endemic focus in the Ecuadorian Andes. Ann Trop Med Parasitol. 1991; 85: 407-411. PMID: 1796881

188. Lawyer PG, Young DG, Butler JF, Akin DE. Development of Leishmania mexicana in Lutzomyia diabolica and Lutzomyia shannoni (Diptera: Psychodidae). J Med Entomol. 1987; 24: 347-355. PMID: 3585930

189. Saldaña A, Chaves LF, Rigg CA, Wald C, Smucker JE, Calzada JE. Clinical cutaneous leishmaniasis rates are associated with household Lutzomyia gomezi, Lu. panamensis, and Lu. trapidoi abundance in Trinidad de Las Minas, western Panama. Am J Trop Med Hyg. 2013; 88: 572-574. doi: 10.4269/ ajtmh.12-0579 PMID: 23339202

190. Akhoundi M, Hajjaran H, Baghaei A, Mohebali M. Geographical Distribution of Leishmania Species of Human Cutaneous Leishmaniasis in Fars Province, Southern Iran. Iran J Parasitol. 2013; 8: 85-91. PMID: 23682265 
191. Svobodova M, Votypka J, Peckova J, Dvorak V, Nasseredin A, Baneth G, et al. Distinct transmission cycles of Leishmania tropica in 2 adjacent foci, Northern Israel. Emerg Infect Dis. 2006; 12: 18601868. PMID: 17326936

192. Akhoundi M, Mohebali M, Asadi M, Mahmodi MR, Amraei K, Mirzaei A. Molecular characterization of Leishmania spp. in reservoir hosts in endemic foci of zoonotic cutaneous leishmaniasis in Iran. Folia Parasitol. 2013; 60: 218-224. PMID: 23951928

193. Rassi Y, Oshaghi MA, Azani SM, Abaie MR, Rafizadeh S, Mohebai M, et al. Molecular detection of Leishmania infection due to Leishmania major and Leishmania turanica in the vectors and reservoir host in Iran. Vector Borne Zoonotic Dis. 2011; 11: 145-150. doi: 10.1089/vbz.2009.0167 PMID: 20575646

194. De Queiroz RG, Vasconcelos IA, Vasconcelos AW, Pessoa FA, de Sousa RN, David JR. Cutaneous leishmaniasis in Ceara state in northeastern Brazil: incrimination of Lutzomyia whitmani (Diptera: Psychodidae) as a vector of Leishmania braziliensis in baturite municipality. Am J Trop Med Hyg. 1994; 50: 693-698. PMID: 8024061

195. De Souza A, Ishikawa E, Braga R, Silveira F, Lainson R, Shaw J. Psychodopygus complexus, a new vector of Leishmania braziliensis to humans in Pará State, Brazil. Trans R Soc Trop Med Hyg. 1996; 90, 112-113. PMID: 8761563

196. Forattini OP, Pattoli DB, Rabello EX, Ferreira OA. Natural infection of Phlebotominae in an enzootic focus of cutaneous leishmaniasis in São Paulo State, Brazil. Rev Saude Publ. 1972; 6: 431-433.

197. Le Pont F, Desjeux P. Leishmaniasis in Bolivia. II. The involvement of Psychodopygus yucumensis and Psychodopygus llanosmartinsi in the selvatic transmission cycle of Leishmania braziliensis braziliensis in a lowland subandean region. Mem Inst Oswaldo Cruz. 1986; 81: 311-318. PMID: 3574129

198. Rangel EF, de Souza NA, Wermelinger ED, Barbosa AF. Natural infection of Lutzomyia intermedia Lutz \& Neiva, 1912, in an endemic area of visceral leishmaniasis of Rio de Janeiro. Mem Inst Oswaldo Cruz. 1984; 79: 395-396. PMID: 6535924

199. Fouque F, Gaborit P, Issaly J, Carinci R, Gantier JC, Ravel C, et al. Phlebotomine sandflies (Diptera: Psychodidae) associated with changing patterns in the transmission of the human cutaneous leishmaniasis in French Guiana. Mem. Inst. Oswaldo Cruz. 2007; 102: 35-40. PMID: 17293996

200. Lainson R, Shaw JJ, Ready PD, Miles MA, Póvoa M. Leishmaniasis in Brazil: XVI. Isolation and identification of Leishmania species from sandflies, wild mammals and man in north Para State, with particular reference to L. braziliensis guyanensis causative agent of "pian-bois." Trans R Soc Trop Med Hyg. 1981; 75: 530-536. PMID: 7324128

201. Lainson R, Shaw JJ, Souza AA, Silveira FT, Falqueto A. Further observations on Lutzomyia ubiquitalis (Psychodidae: Phlebotominae), the sandfly vector of Leishmania (Viannia) lainsoni. Mem Inst Oswaldo Cruz.1992; 87: 437-439. PMID: 1343653

202. Azpurua J, De La Cruz D, Valderama A, Windsor D. Lutzomyia sandfly diversity and rates of infection by Wolbachia and an exotic Leishmania species on Barro Colorado Island, Panama. PLoS Negl Trop Dis. 2010; 4: e627. doi: 10.1371/journal.pntd.0000627 PMID: 20231892

203. Christensen HA, Fairchild GB, Herrer A, Johnson CM, Young DG, de Vásquez AM. The ecology of cutaneous leishmaniasis in the Republic of Panama. J Med Entomol. 1983; 20: 463-484. PMID: 6358496

204. Christensen HA, Herrer A. Attractiveness of sentinel animals to vectors of leishmaniasis in Panama. Am J Trop Med Hyg. 1973; 22: 578-584. PMID: 4729738

205. Morales A, Corredor A, Cáceres E, Ibagos AL, Rodríguez CDe. Aislamiento de tres cepas de Leishmanía à partir de Lutzomyia trapidoi en Colombia. Bioméd. 1981; 1: 198.

206. Braga RR, Lainson R, Ishikawa EAY, Shaw JJ. Leishmania (Viannia) utingensis $\mathrm{n}$. sp., a parasite from the sandfly Lutzomyia (Viannamyia) tuberculata in Amazonian Brazil. Parasite. 2003; 10: 111-118. PMID: 12847917

207. Heisch RB. On Leishmania adleri sp. nov. from lacertid lizards (Latastia sp.) in Kenya. Ann Trop Med Parasitol. 1958; 52: 68-71. PMID: 13521706

208. Maleki N, Javadian E, Mohebali M, DalimiasI AAH, Sadraei J, Zarei ZA, et al. Natural infection of sandflies Sergentomyia dentata in ardebil to lizard Leishmania. Modares J Med Sciences (pathobiol). 2007; 10: 65-73.

209. Garnham PC. The genus Leishmania. Bull World Health Organ. 1971; 44: 477-489. PMID: 5316250

210. Telford SR. Evolutionary implications of Leishmania amastigotes in circulating blood cells of lizards. Parasitol. 1979; 79: 317-324.

211. Wilson VCLC, Southgate BA. Lizard Leishmania. In: Lumsden W.H.R., Evans D.A., editors. Biology of the Kinetoplastida, Vol. 2. Academic Press; London: 1979. pp. 241-268. 
212. Motazedian $\mathrm{H}$, Noyes $\mathrm{H}$, Maingon $\mathrm{R}$. Leishmania and Sauroleishmania: the use of random amplified polymorphic DNA for the identification of parasites from vertebrates and invertebrates. Exp Parasitol. 1996; 83: 150-154. PMID: 8654544

213. Ovezmukhammedov A, Saf'janova VM. Taxonomic problems of the Leishmania of reptiles. Parazitol. 1989; 23: 334-43.

214. Hodukin NI, Sofiev MS. Tr. Uzbek. Inst. Eksp. Med. 1940; 5: 185-217.

215. Desjeux $P$, Waroqw $L$. Mise en evidence du cycle évolutif de la leishmaniose du Gecko Tareentola annulans (Geoffroy Saint-Hilaire, 1823) au Sénégal. Rôle Vecteur de Sergentomyia dubia (Parrot, Mornet \& Cadenat, 1945). Afrique Médicale; 1981: 19, 439-442.

216. McMillan B. Leishmaniasis in the Sudan Republic. 22. Leishmania hoogstraali p. n. in the gecko. J Parasitol. 1965; 51: 336-339. PMID: 5891518

217. Kazemi B, Tahvildar-Bideroni Gh, Hashemi Feshareki SR, Javadian E. Isolation a Lizard Leishmania promastigote from its natural host in Iran. Int J Biol Sci. 2004; 4: 620-623.

218. Nadim A, Seyedi-Rashti MA, Mesghali A. Epidemiology of cutaneous leishmaniasis in Turkeman Sahara, Iran. J Trop Med Hyg. 1968; 71: 238-9. PMID: 5692740

219. Adler $S$, Theodor $O$. The distribution of sandflies and leishmaniasis in Palestine, Syria and Mesopotamia. Ann Trop Med Parasit. 1929; 23: 269-306.

220. Elwasila M. Leishmania tarentolae Wenyon, 1921 from the gecko Tarentola annularis in the Sudan. Parasitol Res. 1988; 74: 591-592. PMID: 3194372

221. Parrot C. Nouvelles recherches sur l'evolution de Leishmania tarentolae chez Phlebotomus minutus Rondani. Bull Soc Pathol Exot. 1935; 28: 958-960.

222. Andrushko AM, Markov GS. The new finding of Leishmania in reptiles of Central Asia. Vestnik Leningrad University, 1995; 1:55-59.

223. Paperna I, Boulard $Y$, Hering-Hagenback SH, Landau I. Description and ultrastructure of Leishmania zuckermani n. sp. amastigotes dandected within the erythrocytes of the South African gecko Pachydactylus turneri Gray, 1864. Parasite. 2001; 8: 349-353. PMID: 11802272

224. Kreutzer RD, Corredor A, Grimaldi G, Grogl M, Rowton ED, Young D G, et al. Characterization of Leishmania colombiensis sp. $\mathrm{n}$ (Kinetoplastida: Trypanosomatidae), a new parasite infecting humans animals, and Phlebotomine sandflies in Colombia and Panama. Am J Trop Med Hyg. 1991; 44: 662675. PMID: 1677544

225. Miles MA, Póvoa MM, de Souza AA, Lainson R, Shaw JJ. Some methods for the enzymic characterization of Latin-American Leishmania with particular reference to Leishmania mexicana amazonensis and subspecies of Leishmania hertigi. Trans R Soc Trop Med Hyg. 1980; 74: 243-252. PMID: 7385303

226. Furuya M, Motonari S, Akimaru Y, Mimori T, Gomez EA, Hashiguchi Y. Natural infection of Lutzomyia hartmanni with Leishmania (V.) equatorensis in Ecuador. Parasitol Int. 1998; 47: 121-126.

227. Herrer A. Leishmania hertigi sp. n., from the tropical porcupine, Coendou rothschildi Thomas. J Parasitol. 1971; 57: 626-629. PMID: 5090970

228. Rose K. Cutaneous leishmaniasis in red kangaroos. Aust Vet J. 2004; 82: 440. PMID: 15354854

229. Marcondes CB, Santos-Neto LG., Lozovei AL. Ecology of phlebotomine sandflies (Diptera, Psychodidae) in Brazilian Atlantic Forest. Rev Soc Bras Med Trop. 2001; 34: 255-260. PMID: 11460211

230. Desbois N, Pratlong F, Quist D, Dedet J. Leishmania (Leishmania) martiniquensis n. sp. (Kinetoplastida: Trypanosomatidae), description of the parasite responsible for cutaneous leishmaniasis in Martinique Island (French West Indies). Parasite. 2014; 21: 12. doi: 10.1051/parasite/2014011 PMID: 24626346

231. Pothirat $T$, Tantiworawit $A$, Chaiwarith $R$, Jariyapan $N$, Wannasan $A$, Siriyasatien $P$, et al. First Isolation of Leishmania from Northern Thailand: Case Report, Identification as Leishmania martiniquensis and Phylogenetic Position within the Leishmania enriettii Complex. PLoS Negl Trop Dis.2014; 8: e3339. doi: 10.1371/journal.pntd.0003339 PMID: 25474647

232. Bualert $L$, Charungkiattikul $W$, Thongsuksai $P$, Mungthin $M$, Siripattanapipong $S$, Khositnithikul $R$, et al. Autochthonous disseminated dermal and visceral leishmaniasis in an AIDS patient, southern Thailand, caused by Leishmania siamensis. Am J Trop Med Hyg. 2012; 86: 821-824. doi: 10.4269/ ajtmh.2012.11-0707 PMID: 22556080

233. Kanjanopas K, Siripattanapipong S, Ninsaeng U, Hitakarun A, Jitkaew S, Kaewtaphaya P, et al. Sergentomyia (Neophlebotomus) gemmea, a potential vector of Leishmania siamensis in southern Thailand. BMC Infect Dis. 2013; 13, 333. doi: 10.1186/1471-2334-13-333 PMID: 23870062

234. Sukmee T, Siripattanapipong S, Mungthin M, Worapong J, Rangsin R, Samung $Y$, et al. A suspected new species of Leishmania, the causative agent of visceral leishmaniasis in a Thai patient. Int J Parasitol. 2008; 38: 617-22. doi: 10.1016/j.ijpara.2007.12.003 PMID: 18262531 